\title{
Cenários de Desenvolvimento Urbano e Periurbano em Japeri, RJ: zona de sacrifício ou município insurgente?
}

Urban and Periurban Development Scenarios in Japeri, RJ: sacrificial zone or insurgent territory?

Escenarios de desarrollo urbano y periurbano en Japeri, RJ: ¿zona de sacrificio o municipio insurgente?

Scénarios de développement urbain et périurbain à Japeri, RJ : zone de sacrifice ou municipalité insurgé?

Denise de Alcantara, Natália da Silva Oliveira, Lígia Castanheira Magalhães e Gabriel Rodrigues de Mendonça

\section{(2) OpenEdition}

\section{Journals}

\section{Edição electrónica}

URL: http://journals.openedition.org/espacoeconomia/16368

DOI: 10.4000/espacoeconomia. 16368

ISSN: 2317-7837

\section{Editora}

Núcleo de Pesquisa Espaço \& Economia

\section{Refêrencia eletrónica}

Denise de Alcantara, Natália da Silva Oliveira, Lígia Castanheira Magalhães e Gabriel Rodrigues de Mendonça, «Cenários de Desenvolvimento Urbano e Periurbano em Japeri, RJ: zona de sacrifício ou município insurgente? », Espaço e Economia [Online], 19 | 2020, posto online no dia 01 setembro 2020, consultado o 09 setembro 2020. URL : http://journals.openedition.org/espacoeconomia/16368; DOI : https://doi.org/10.4000/espacoeconomia.16368

Este documento foi criado de forma automática no dia 9 setembro 2020.

(C) NUPEE 


\title{
Cenários de Desenvolvimento
} Urbano e Periurbano em Japeri, RJ: zona de sacrifício ou município insurgente?

\author{
Urban and Periurban Development Scenarios in Japeri, RJ: sacrificial zone or \\ insurgent territory?
}

Escenarios de desarrollo urbano y periurbano en Japeri, RJ: ¿zona de sacrificio o municipio insurgente?

Scénarios de développement urbain et périurbain à Japeri, RJ : zone de sacrifice ou municipalité insurgé?

Denise de Alcantara, Natália da Silva Oliveira, Lígia Castanheira Magalhães e Gabriel Rodrigues de Mendonça

\section{Introdução}

1 As desigualdades socioeconômicas visíveis nas cidades periféricas brasileiras, a partir de um perverso e segregacionista processo histórico de industrialização e metropolização, com salários baixos e concentração de investimentos e infraestruturas em áreas privilegiadas reflete-se na periferia metropolitana fluminense, que abriga populações destituídas do direito à cidade ou à justiça ambiental. Nosso estudo focaliza o município de Japeri, localizado no Oeste Metropolitano do Rio de Janeiro (OM), identificado como zona de sacrifício (Pereira, 2013; Silva; Bueno, 2013) e marcado pelo estigma da pobreza e da violência (Alcantara et al., 2019).

2 Este trabalho investiga e analisa as fragilidades e potenciais socioambientais, bem como o impacto de políticas públicas e seus rebatimentos sobre o território e a produção urbana de Japeri, a partir de seu enquadramento como zona de sacrifício, formulado no âmbito do estudo do desenvolvimento urbano. 
O município é vítima do progresso e da expansão da metrópole, com prejuízos ao meio ambiente, falta de investimentos em infraestrutura urbana, usos do solo com ocupação irregular, e atividades econômicas indesejáveis (aterro sanitário) e geradoras de impactos ambientais (mineradoras e indústrias poluentes), próximos a lugares habitados por populações pobres. Sua economia tem como principal base o comércio e serviços e comprometimento de $81 \%$ da receita com o custeio da máquina administrativa. De suas receitas totais $85 \%$ são provenientes das transferências federais, estaduais, participações governamentais, além vinculadas aos royalties do petróleo, perfazendo $14 \%$ de sua receita total (TCE, 2011). Mesmo com baixa contribuição do PIB per capita ( $\mathrm{R} \$ 15.956,10)$ ficando em 92a. posição em relação ao Estado do Rio de Janeiro, garante concessão de renúncias fiscais a empresas e indústrias.

Com os baixos índices socioeconômicos, o desenvolvimento urbano e social de Japeri é comprometido ainda pelo crescimento da violência, do tráfico e do poder paramilitar, que domina várias localidades e influencia negativamente os índices de segurança pública, além de abrigar instalações de unidades prisionais no território, que ampliam a percepção negativa na imagética do município (Alcantara et al., 2019). Os conflitos socioambientais, institucionais e econômicos são fatores determinantes para a manutenção dos índices de violência e das carências sociais de Japeri, comprovadas pelo IDH-M de 0,659 (IBGE 2010) e pelo IBEU de 0,573 (a 5480ª . colocação entre 5565 municípios analisados pelo Observatório das Metrópoles). Nos planos e projetos institucionais de desenvolvimento regional, o município é tratado como espaço de expansão industrial e logística (Câmara Metropolitana, 2018).

5 Tais desafios definem no município uma crise tanto institucional quanto socioeconômica envolvendo a governança pública. Temos em conta que, dentre as atribuições da gestão municipal, incluindo seu corpo técnico, previstas na Constituição Federal de 1988 (CF-88), destacam-se: definir a aplicação dos recursos e verbas repassadas pelo Estado e União; administrar o transporte coletivo; fomentar a educação básica; prestar serviços de saúde; promover o ordenamento do solo urbano e território e proteger o patrimônio histórico-cultural. Tais fatores são determinantes na busca de soluções para os problemas de violência urbana e carências sociais e, quando não efetivados, podem indicar tanto má governança municipal, quanto negligência do Estado. Japeri torna-se um reflexo da produção urbana sem o interesse de integrar o desenvolvimento conjunto entre metrópole e periferia. 
Figura 1 - Mapa de áreas urbanizadas com a localização do município de Japeri (inscrita no círculo) em relação a RMRJ

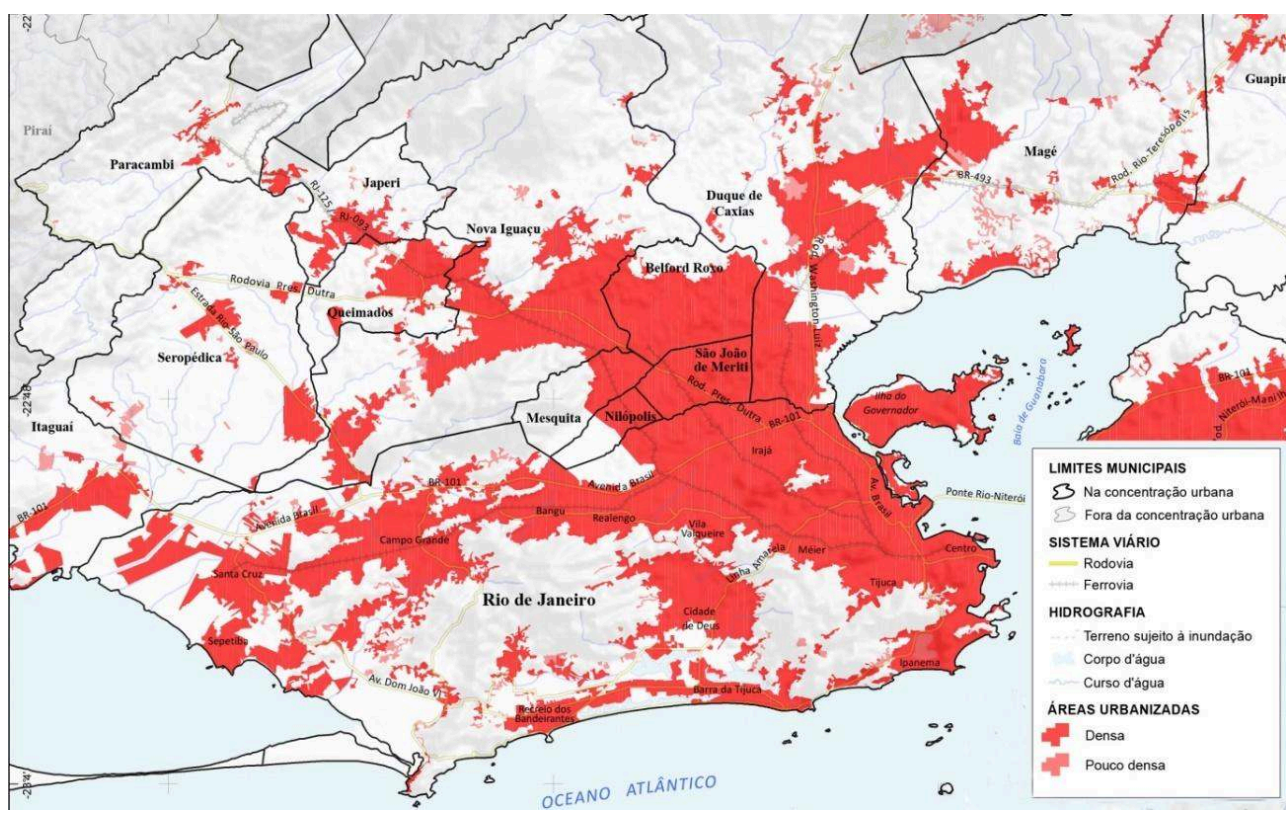

Fonte: IBGE, Ano: 2018, editado pelo GEDUR.

6 Este artigo apresenta um dos estudos de caso vinculados ao estudo maior e mais abrangente sobre o Oeste Metropolitano intitulado de Territórios e paisagens perimetropolitanos: conflitos e desigualdades sócio-espaciais e cenários prospectivos no Rio de Janeiro na perspectiva da Nova Agenda Urbana 20301. A pesquisa é desenvolvida no âmbito do GEDUR-UFRRJ ${ }^{2}$ e incorpora a metodologia desenvolvida pelo Grupo SELRJ/UFRJ (Alcantara, 2020; Tângari et al., 2012). De cunho empírico e exploratório, as análises abarcam temáticas distintas relacionadas ao desenvolvimento e gestão, às redes e fluxos, às centralidades urbanas e à paisagem e planejamento. A investigação interdisciplinar e multiescalar envolve desde a escala macro da região metropolitana até a escala local, dos núcleos urbanos e suas problemáticas sócio-espaciais (Souza, 2015). Os dados socioeconômicos oficiais são obtidos no IBGE Cidades (2019), TCE (2011) e prefeitura municipal, relacionando informação sobre moradia e renda no município, destacando a relação das desigualdades e refletindo sobre espaço construído e a sua apropriação.

Dentre as revisões e aprofundamentos conceituais realizados, destacam-se aqueles relacionados ao desenvolvimento urbano sustentável e aos espaços livres de edificações e esfera pública (TÂNGARI et al., 2009), a partir dos quais foram levantadas reflexões relativas à Japeri, incorporando sua história, evolução urbana e e inserção metropolitana. Baseado-nos no conceito de cidade como organização humana, definido por Raquel Rolnik $(2009$, p. 9) como a "materialização da sua própria história", foram reunidos fatos históricos para que ajudam a esclarecer as causas da realidade atual do município. O conceito de cidade política, da mesma autora, define que a construção da cidade implica na relação social interpessoal, com noções de coletividade, em que nunca se está só e que toda e qualquer aglomeração de indivíduos, em meios urbanos de grande ou pequeno porte, necessita de um poder político-administrativo (Rolnik, 2009). Nesse sentido, entendemos que a coesão territorial deve englobar todos os atores sociais e institucionais que participam e estão envolvidos na produção urbana e 
periurbana, que, por sua vez, incorpora o entendimento das noções de espaços livres de edificações (Magnoli, 2006; Tângari, et al., 2009) e sistema de espaços livres, já que nosso foco recai sobre a forma, a apropriação e o uso dos espaços livres públicos e coletivos .

8 A produção de mapas e análises espaciais elaboradas na escala meso (setorial, representativa dos municípios), sistematizam os aspectos levantados em visitas de campo e por análise aerofotogramétrica relativos a: (a) suporte territorial - topografia, redes, transportes e hidrografia; (b) aspectos legislativos - macrozoneamento previsto no PDM sobreposto às manchas de ocupação urbana; (c) unidades de paisagem ou morfo-territoriais (Silva et al., 2015) - identificação de manchas similares de suporte físico, padrão de drenagem, cobertura vegetal e mancha urbana/padrões de ocupação; e (d) mapa síntese da paisagem, com os elementos estruturadores do território. As bases cartográficas foram geradas a partir de bases oficiais, utilizando geotecnologias livres e aplicativos de georreferenciamento (Google Earth, ArcGis), e possibilitaram a delimitação dos espaços livres de edificações existentes e a categorização de uso e apropriação, das condições da cobertura vegetal, topográficas e morfológicas municipais. Permitiram ainda a delimitação das manchas de ocupação urbana consolidada e em consolidação, a identificação dos vetores de expansão e as principais redes viárias e de fluxos. Sua sobreposição esclareceu aspectos concordantes, discordantes, conflitos e contradições, entre os elementos estruturadores da paisagem e os aspectos morfoterritoriais.

9 Com o desenvolvimento da investigação, foi identificada a necessidade de elaboração de um mapa da violência, cujos dados foram extraídos de notícias relacionadas à eventos policiais em bases jornalísticas, reúne e demarca as áreas com ocorrência de casos de violência contra a vida humana e a propriedade. Seja do tráfico, das milícias, de crimes de vários espectros, a análise compara e espacializa sua localização e o nível de desenvolvimento urbano dos locais onde ocorrem. Ressalta-se que as notícias veiculadas sobre o município pelos meios jornalísticos, sejam os de grande veiculação, sejam os locais, reforçam a imagem de território hostil e perigoso, contribuindo com o desígnio de zona de sacrifício (Silva; Bueno, 2013).

10 No estudo empírico sobre o município torna-se perceptível a política estatal que por décadas negligencia a periferia e influencia diretamente na crescente violência e desigualdade social. Apesar da imagem negativa, Japeri possui um legado histórico significativo e um patrimônio edificado e ambiental potencial (Reis; Alcantara, 2019), além de grupos sociais e comunitários ativos e atuantes, que vem buscando proteger e valorizar suas potencialidades ambientais e econômicas. Suas ações indicam a importância do estímulo à atividades agropastoris de pequeno porte (agricultura familiar e orgânica), com pequenos proprietários, bem como às atividades de lazer e turismo ecológico, pela existência de florestas, montanhas e rios, com possíveis desdobramentos na melhoria da economia local.

11 Serão estas, então, as formas de resiliência urbana que possam a fomentar o uso e a apropriação do espaço urbano e do território de forma mais justa e equitativa? Quais seriam as políticas e ações para evitar uma expansão urbana e industrial danosa, ambiental e socialmente e reprodutora de um padrão perverso, desequilibrado e injusto de urbanização que concentra a riqueza no centro metropolitano e dissemina a pobreza pelas periferias? 
Este artigo está estruturado em três partes que narram de forma sistematizada o desenvolvimento da investigação. A primeira contextualiza o território socioeconômica e ambientalmente e sua evolução urbana, refletindo os dados estatísticos e demográficos. A segunda parte aprofunda as potencialidades e fragilidades identificadas apresentando a produção cartográfica produzida pelo grupo de pesquisa e as análises espaciais realizadas. A terceira parte, propositiva, indica alguns caminhos possíveis a partir da análise de cenários. As conclusões refletem os resultados apurados da pesquisa em desenvolvimento e as etapas a serem cumpridas.

\section{Formação e evolução do município de Japeri}

13 Situado no sopé das escarpas da Serra do Mar, Japeri divide seus limites ao noroeste com Paracambi, a norte e nordeste com Miguel Pereira e Nova Iguaçu, a sudeste com Queimados e a sudoeste com Seropédica, tendo como principal limite geográfico o Rio Guandu. Os principais acessos ao município eram as rodovias estaduais RJ-125 e RJ-093, partindo da Rodovia Presidente Dutra (BR-116) até 2014, quando entra em operação do Arco Metropolitano, rodovia logística implantada com o objetivo de interligar dois importantes polos logísticos/industriais metropolitanos (o Porto de Itaguaí e o COMPERJ, em Itaboraí). A obra culmina, na porção oeste metropolitana, com a fragmentação dos territórios das planícies flúvio-marinhas que atravessa, caracterizados por grandes tratos de terras não urbanizadas e ocupadas por atividades agropastoris ou cobertura vegetal, mais facilmente desapropriadas, e pontuados com manchas de ocupação urbana consolidada e em consolidação (Alcantara et al., 2019). Similarmente, em Japeri o Arco perpassa espaços livres de edificações dedicados à atividades agropastoris, por áreas de forrações e ainda por fragmentos florestados. (Fig. 2).

14 A história do município se confunde com o desenvolvimento da própria Baixada Fluminense, onde se insere, região que, até meados do século XIX, tinha como principal atividade econômica o plantio de cítricos e outros produtos agrícolas (Silva, 2017). A formação urbana da Baixada é relevante neste estudo pois reforça o caráter segregacionista e a relação centro-periferia impetrados pelo poder público, que expulsou para as periferias os pobres e os usos indesejados (Maricato, 2001). No século XVIII, batizada como Morgado de Belém, a vila recebe em 1858 a estação de Belém da Estrada de Ferro Dom Pedro II - que interligaria o Rio de Janeiro aos estados de São Paulo e Minas Gerais - última estação do trecho no sopé da Serra das Araras, hoje correspondente ao Ramal Japeri da Supervia. Vale mencionar o valor simbólico histórico e arquitetônico da Estação de Belém (Reis e Alcantara, 2019), casarão construído em 1858 em estilo enxaimel, que desde 2018 passa por obras de restauração para abrigar algumas atividades culturais, além das logísticas ${ }^{3}$. (Fig. 3). 
Figura 2 - Mapa síntese da paisagem de Japeri; elaborado por Lígia Magalhães

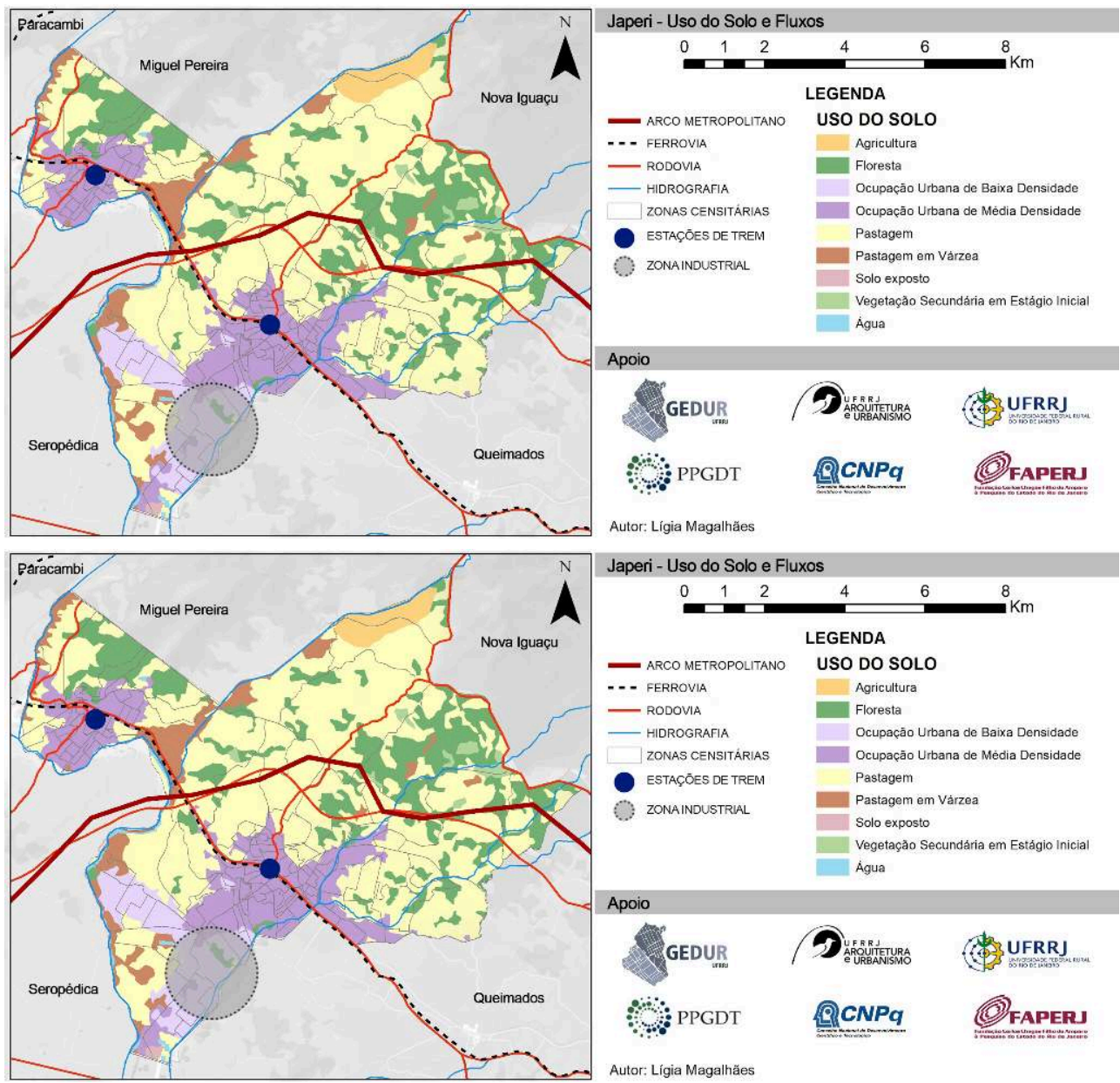

15 Fonte:Acervo GEDUR

16 Naquela época a rede ferroviária chegou a transportar 51 mil passageiros, além de propiciar o escoamento de produtos agrícolas. Somente em 1896, é inaugurada a Estação de Caramujos, atual Engenheiro Pedreira, que assim como na antiga Belém, propicia o início da ocupação urbana em seu entorno. ${ }^{4}$ Ambas as localidades passam a ser distritos de Nova Iguaçu na década de 1950. 
Figura 3 - Estação Belém em 1909

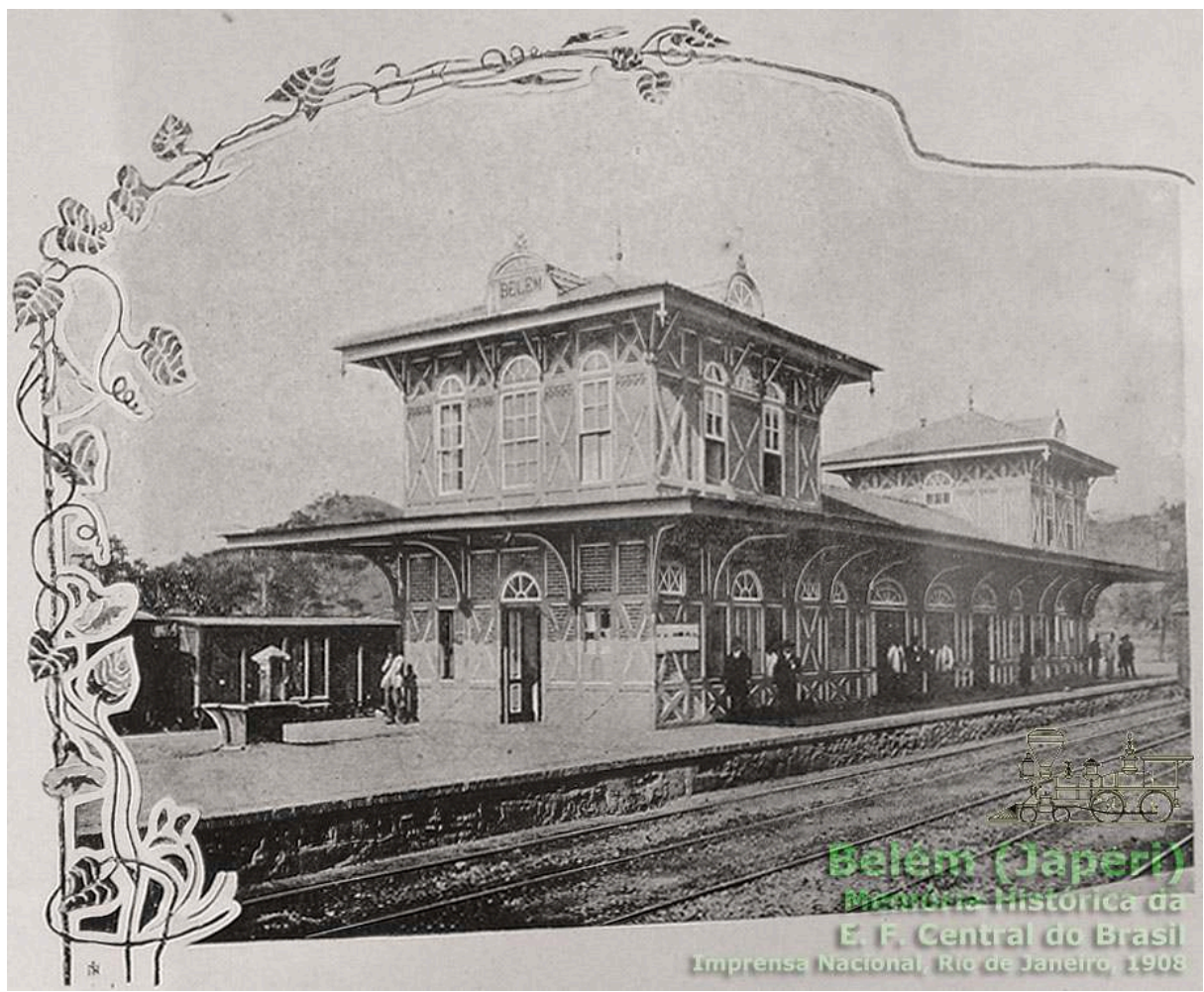

Fonte: Portal Memória Histórica da E.F. Central do Brasil ${ }^{5}$

17 Na primeira metade do século XX, a atividade econômica predominante era a primária, com usos do solo destinados às atividades agrícolas e pastoris. A queda da exportação de cítricos, na II Grande Guerra, e o ataque de uma praga que dizimou praticamente toda a produção na Baixada Fluminense, fez com que os proprietários loteassem suas terras improdutivas, sem qualquer infraestrutura, cujos preços baixos e a oferta de transporte ferroviário atraiu as populações mais pobres que passaram a ocupá-las com moradias marcadas pela autoconstrução (Maia; Rodrigues, 2009). Entre as décadas de 1940 e 1950, o expressivo aumento populacional em Nova Iguaçu fomentou as primeiras emancipações municipais, de Duque de Caxias, São João de Meriti e Nilópolis, pelo descontentamento da gestão municipal central com os distritos desassistidos. Várias décadas depois, após a promulgação da $\mathrm{CF}-88$, a redemocratização e a garantia de maior autonomia administrativa dos municípios, em um processo político conturbado, houve uma primeira tentativa de emancipação frustrada, que logrou êxito em 1991.

Sua segunda tentativa de emancipação foi iniciada a partir da constituição de uma Comissão que contava com a presença de vereadores, líderes religiosos, associações de moradores etc, enfim, tratava-se de um grupo bastante heterogêneo. $O$ projeto do plebiscito foi aprovado na ALERJ e o mesmo foi marcado para junho de 1991. A campanha foi intensa e tinha dois focos: primeiro, buscava criar nos moradores, uma identidade territorial própria haja vista, [...], aquele distrito, ao longo de sua história ter integrado diferentes localidades; e, em segundo lugar, se voltava contra a indiferença dispensada pela prefeitura e pelos políticos de Nova Iguaçu ao distrito de Japeri e seus moradores, que viviam em péssimas condições de vida. 0 comparecimento da população no dia do plebiscito foi em massa, de forma que, em dezembro de 1991 foi aprovada a lei que criava aquele município e, em 1992, foram realizadas as primeiras eleições municipais, tendo em 1993, sido empossado o primeiro prefeito (Maia; Rodrigues, 2009, p. 3882). 

em 2019, de 104,768 habitantes, perfazendo uma densidade demográfica de 1.282,50 hab $/ \mathrm{km}^{2}$ (IBGE-Cidades, 2019). A população se concentra principalmente no entorno dos dois núcleos principais, Japeri e Engenheiro Pedreira, que configuram fragmentos urbanos adensados e desconectados entre si, com o restante do território configurado por áreas de rarefeita ocupação urbana, ou espaços livres de edificações (Magnoli, 2006). Com uma taxa de crescimento demográfico da ordem de $20 \%$ desde o último Censo (IBGE, 2019), e sem investimentos ou projetos de melhorias urbanas e infraestruturais, o município apresenta desafios de ordem política, urbana e social e é marcado pela desigualdade socioespacial; pelos baixos índices de desenvolvimento humano e urbano em relação ao núcleo metropolitano; pela falta de investimento em infraestrutura e saneamento; pela urbanização precária; e pelas carências de serviços públicos e assistência à população. (Tabela 1).

Tabela 1 - Dados censitários de Japeri

\begin{tabular}{|l|l|l|l|l|l|l|l|l|}
\hline Município & $\begin{array}{l}\text { Pop. } \\
\text { censo } \\
2000\end{array}$ & $\begin{array}{l}\text { Pop. } \\
\text { censo } \\
2010\end{array}$ & $\begin{array}{l}\text { Pop. est. } \\
2018\end{array}$ & $\begin{array}{l}\text { Cresc. } \\
\text { Pop. } \\
2000-2018\end{array}$ & $\begin{array}{l}\text { Área } \\
\mathrm{km}^{2}\end{array}$ & $\begin{array}{l}\text { Dens. } \\
\text { Demogr. }\end{array}$ & IDHM & $\begin{array}{l}\text { PIB per } \\
\text { capita } \\
2016\end{array}$ \\
\hline $\begin{array}{l}\text { Rio de } \\
\text { Janeiro }\end{array}$ & 5.857 .904 & 6.320 .446 & 6.688 .927 & $12,5 \%$ & $1.200,18$ & $5.265,82$ & 0,799 & $50.690,82$ \\
\hline Japeri & 83.278 & 95.492 & 103.960 & $20,0 \%$ & 81,69 & $1.166,37$ & 0,659 & $12.874,11$ \\
\hline
\end{tabular}

Fonte: IBGE (2019)

21 O IDH-M passou de 0,529 em 2000 para 0,659 em 2010, um aumento de $24,57 \%$. No entanto, ainda é considerado um dos piores índices do Estado do Rio de Janeiro. Mesmo com o aumento da renda per capita média em $78,71 \%$ na última década, a realidade observada e vivenciada pela população se mostra diferente dos dados, assim como a de outros municípios da RMRJ. $O$ índice GINI de 0,42, demonstra certo equilíbrio de renda, levando-se em conta que a renda per capita atingia apenas $\mathrm{R} \$ 420,00$, em 2010 e que a porcentagem de pobres e extremamente pobres alcançava quase $20 \%(14,19 \%$ e $4,09 \%$, respectivamente) (PNUD, 2013), com 25,9\% dependentes do Bolsa-Família (Casa Fluminense, 2020).

Com base nos dados obtidos no Censo 2010 (Britto et al, 2016), quase 100\% da população tinha acesso a água potável em Japeri, e aproximadamente $85 \%$ dos domicílios eram atendidos pela coleta de lixo. No entanto, tais dados contrastam com dados levantados em campo e com relatos obtidos pelos pesquisadores ${ }^{6}$ relativos a outros aspectos de infraestrutura urbana. A mais recente publicação da Casa Fluminense ${ }^{7}$ sobre os índices de desigualdades da RMRJ atesta esta discrepância. Com efeito, de acordo com os Mapas da Desigualdade (Casa Fluminense, 2020), apenas $72,4 \%$ dos domicílios têm abastecimento de água (não sendo considerado nessa porcentagem qualidade ou regularidade no abastecimento. Ainda que o IBGE indique 68,3\% dos domicílios com esgotamento adequado, não há rede de coleta nem qualquer sistema de tratamento do esgoto; o esgoto que não é coletado em fossas sépticas domiciliares ou em estações nas instalações industriais, é lançado in natura diretamente nos afluentes do Rio Guandu, 
cuja água abastece 9 milhões de pessoas na metrópole. A Tabela 2 apresenta dados comparativos entre Japeri e o município do Rio de Janeiro.

Tabela 2 - Aspectos urbanísticos de Japeri

\begin{tabular}{|l|l|l|l|}
\hline Município & Esgotamento adequado & Arborização Urbana & Urbanização vias públicas \\
\hline Rio de Janeiro & $94,4 \%$ & $70,5 \%$ & $78,4 \%$ \\
\hline Japeri & $68,3 \%$ & $25,7 \%$ & $26,8 \%$ \\
\hline
\end{tabular}

Fonte: IBGE (2019)

\section{Tabela 3 - Índice de Bem-Estar Urbano - Ranking dos Municípios da RMRJ}

\begin{tabular}{|c|c|c|c|c|c|c|c|}
\hline Município & $\begin{array}{l}\text { D1 } \\
\text { Mobilidade }\end{array}$ & $\begin{array}{l}\text { D2 } \\
\text { Ambiente }\end{array}$ & $\begin{array}{l}\text { D3 } \\
\text { Habitação }\end{array}$ & $\begin{array}{l}\text { D4 } \\
\text { Ac.Serv. }\end{array}$ & $\begin{array}{l}\text { D5 } \\
\text { Infraestrutura }\end{array}$ & IBEU & $\begin{array}{l}\text { Posição } \\
\text { Nacional }\end{array}$ \\
\hline Niterói & 0,709 & 0,890 & 0,865 & 0,926 & 0,747 & 0,827 & $1531^{\circ}$ \\
\hline Rio Bonito & 0,905 & 0,893 & 0,881 & 0,774 & 0,657 & 0,822 & $1635^{\circ}$ \\
\hline Rio de Janeiro & 0,691 & 0,865 & 0,823 & 0,948 & 0,771 & 0,819 & $1707^{\circ}$ \\
\hline Nilópolis & 0,596 & 0,887 & 0,858 & 0,965 & 0,769 & 0,815 & $1813^{\circ}$ \\
\hline Paracambi & 0,773 & 0,931 & 0,815 & 0,859 & 0,662 & 0,808 & $1995^{\circ}$ \\
\hline Petrópolis & 0,822 & 0,771 & 0,850 & 0,806 & 0,638 & 0,778 & $2796^{\circ}$ \\
\hline $\begin{array}{l}\text { Cachoeiras } \\
\text { Macacu }\end{array}$ & 0,891 & 0,847 & 0,835 & 0,781 & 0,530 & 0,777 & $2809^{\circ}$ \\
\hline Itaguaí & 0,875 & 0,741 & 0,812 & 0,849 & 0,601 & 0,776 & $2850^{\circ}$ \\
\hline Mesquita & 0,601 & 0,812 & 0,831 & 0,933 & 0,640 & 0,764 & $3174^{\circ}$ \\
\hline Guapimirim & 0,789 & 0,902 & 0,811 & 0,690 & 0,623 & 0,763 & $3181^{\circ}$ \\
\hline $\begin{array}{l}\text { São João de } \\
\text { Meriti }\end{array}$ & 0,598 & 0,716 & 0,802 & 0,943 & 0,665 & 0,745 & $3628^{\circ}$ \\
\hline Duque de Caxias & 0,611 & 0,770 & 0,801 & 0,818 & 0,689 & 0,738 & $3809^{\circ}$ \\
\hline Tanguá & 0,797 & 0,899 & 0,808 & 0,701 & 0,465 & 0,734 & $3885^{\circ}$ \\
\hline Nova Iguaçu & 0,528 & 0,797 & 0,816 & 0,854 & 0,586 & 0,716 & $4234^{\circ}$ \\
\hline São Gonçalo & 0,619 & 0,666 & 0,847 & 0,815 & 0,518 & 0,693 & $4611^{\circ}$ \\
\hline Seropédica & 0,717 & 0,755 & 0,808 & 0,809 & 0,365 & 0,691 & $4652^{\circ}$ \\
\hline
\end{tabular}




\begin{tabular}{|l|l|l|l|l|l|l|l|}
\hline Magé & 0,644 & 0,796 & 0,795 & 0,664 & 0,489 & 0,678 & $4815^{\circ}$ \\
\hline Queimados & 0,434 & 0,806 & 0,789 & 0,819 & 0,512 & 0,672 & $4872^{\circ}$ \\
\hline Belford Roxo & 0,471 & 0,684 & 0,773 & 0,807 & 0,517 & 0,650 & $5071^{\circ}$ \\
\hline Itaboraí & 0,639 & 0,677 & 0,836 & 0,599 & 0,336 & 0,617 & $5310^{\circ}$ \\
\hline Maricá & 0,658 & 0,712 & 0,866 & 0,476 & 0,298 & 0,602 & $5388^{\circ}$ \\
\hline Japeri & 0,355 & 0,667 & 0,737 & 0,750 & 0,354 & 0,573 & $5480^{\circ}$ \\
\hline
\end{tabular}

Fonte: Editados pelos autores a partir da tabela IBEU_municipal_basedados (OBSERVATÓRIO, 2019).

27 Os dados acima, nada animadores, ratificam a situação precária do município em termos de infraestrutura e urbanização. O Índice de Bem-Estar Urbano (IBEU) inclui cinco dimensões urbanas, expandindo as categorias de análise que o IDHM não contempla: mobilidade, condições ambientais, habitação, acesso a serviços e infraestrutura. Para Japeri, o IBEU de 0,745 alcança baixa colocação, $5480^{a}$ lugar, dentre 5655 municípios brasileiros pesquisados. Dentre os 92 municípios fluminenses, Japeri figura em último lugar quanto ao bem-estar urbano (Observatório, 2019). $\mathrm{Na}$ análise segmentada, a dimensão mobilidade atinge 0,355 , sendo um dos piores índices em termos nacionais, refletindo um quadro que afeta toda a RMRJ, incluindo o município carioca, com apenas 0,691. Na dimensão infraestrutura urbana, Japeri alcança 0,354, enquanto o Rio de Janeiro, 0,771. A Tabela 3 apresenta o ranking do IBEU para os 22 municípios metropolitanos fluminenses, com destaque para Japeri e os outros quatro municípios do OM - Itaguaí, Seropédica, Queimados e Paracambi.

As carências infraestruturais e urbanísticas se refletem ainda no nexo trabalho e mobilidade. Em função da baixa oferta de postos de trabalho formal no município, os principais destinos da mão-de-obra se direcionam ao Centro e à Barra da Tijuca, bairro nobre da zona oeste do município do Rio de Janeiro. Verifica-se que a maior parte da população trabalhadora não está empregada em Japeri, apesar do crescimento econômico e industrial verificado nos últimos anos. A taxa de empregabilidade em relação a população se limita a $6,4 \%$; cerca de $46 \%$ dos trabalhadores trabalham sem registro formal; $55 \%$ trabalham fora do município de Japeri, sendo $44 \%$ no Rio de Janeiro. Outro indicador relevante é a diferença salarial entre brancos e negros, que atinge $31,6 \%$, sendo que $66 \%$ da população japeriense se auto-declara negra (Casa Fluminense, 2018; 2020). Os dados acima confirmam a grande dependência do transporte público, principalmente pelo ramal ferroviário, e o desconforto do movimento pendular diário. De fato, Japeri figura entre os piores municípios em termos de tempo no deslocamento pendular (LAGO, 2007). A precariedade na mobilidade se faz presente nos deslocamentos intramunicipais, com linhas de ônibus precárias e insuficientes e serviços de vans, nem sempre legais e controlados. Assim, 43,6\% da população japeriense tem no transporte ativo (a pé ou de bicicleta) seu grande aliado (Casa Fluminense, 2020). Os levantamentos realizados reafirmam o argumento quanto às deficiências de mobilidade e infraestrutura municipais, que geram desigualdades urbanas e sociais na metrópole (Ribeiro, 2016) e pela análise acima exposta, o município 
pode ser caracterizado, não somente como zona de sacrifício, mas também como cidade-dormitório (OJIMA et al., 2007).

\section{Vivências e cartografias - o olhar de dentro para fora} pencialidades, implica em que pesquisadores tenham que sair de sua zona de conforto. Assim, visitas de campo foram realizadas em ocasiões diversas e com objetivos distintos. Para o trabalho aqui apresentado, fizemos três incursões por diversos pontos de interesse relacionados à cidade e ao território. Em uma delas, a mais abrangente, partimos da Estação Japeri e percorremos os bairros de Japeri Centro e Nova Belém, atingindo as margens do Rio Guandu; ao cruzar a linha férrea a direção tomada foi a sede da Prefeitura, localizada entre os dois principais núcleos urbanos, localizada na Estrada Ari Schiavo; ainda naquele percurso, outros bairros foram percorridos até a Pedra Lisa, onde houve parada para almoço e para conhecer um dos pontos turísticos locais, o morro homônimo, onde jovens da baixada praticam rapel e escalada. Nesse trecho do percurso expressa as carências urbanas e infraestrurais já mensionadas, com muitas vias sequer asfaltadas, iluminação pública precária, valões de esgoto a céu aberto, lixo e entulho depositado nas vias. 
Figura 4 - Bairros de Japeri

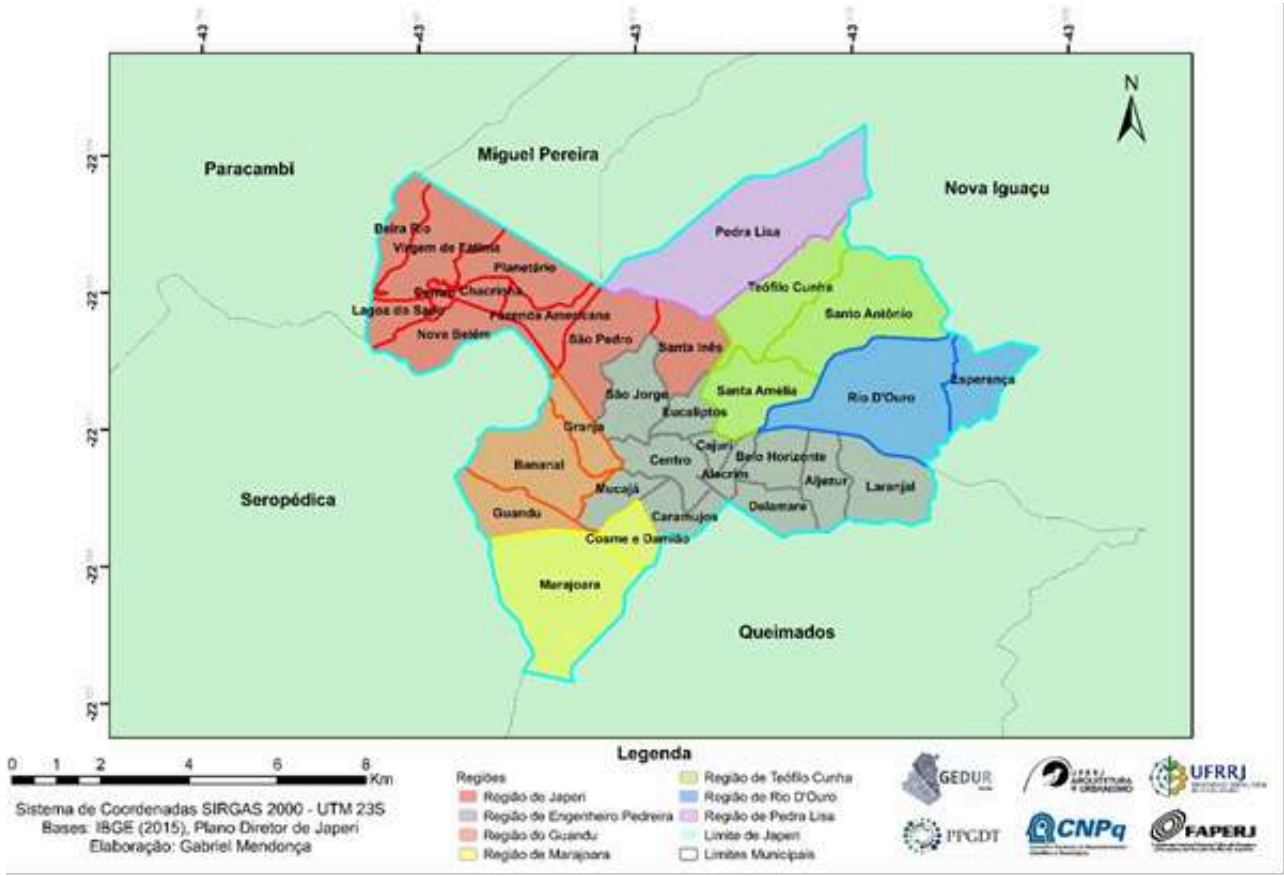

Fonte: Mapa elaborado por Gabriel Almeida com dados do PDM. Acervo Gedur.

o Centro de Engenheiro Pedreira foi a parada seguinte, antes do percurso pelo Distrito Industrial, onde se localiza a fábrica da Granado. Apesar da existência do Distrito Industrial, foram observadas muitas plantas fabris desativadas. (Figs. 5 a 8).

Figura 5 - Visita de Campo realizada em Japeri em dezembro de 2018: Às Margens Do Rio Guandu

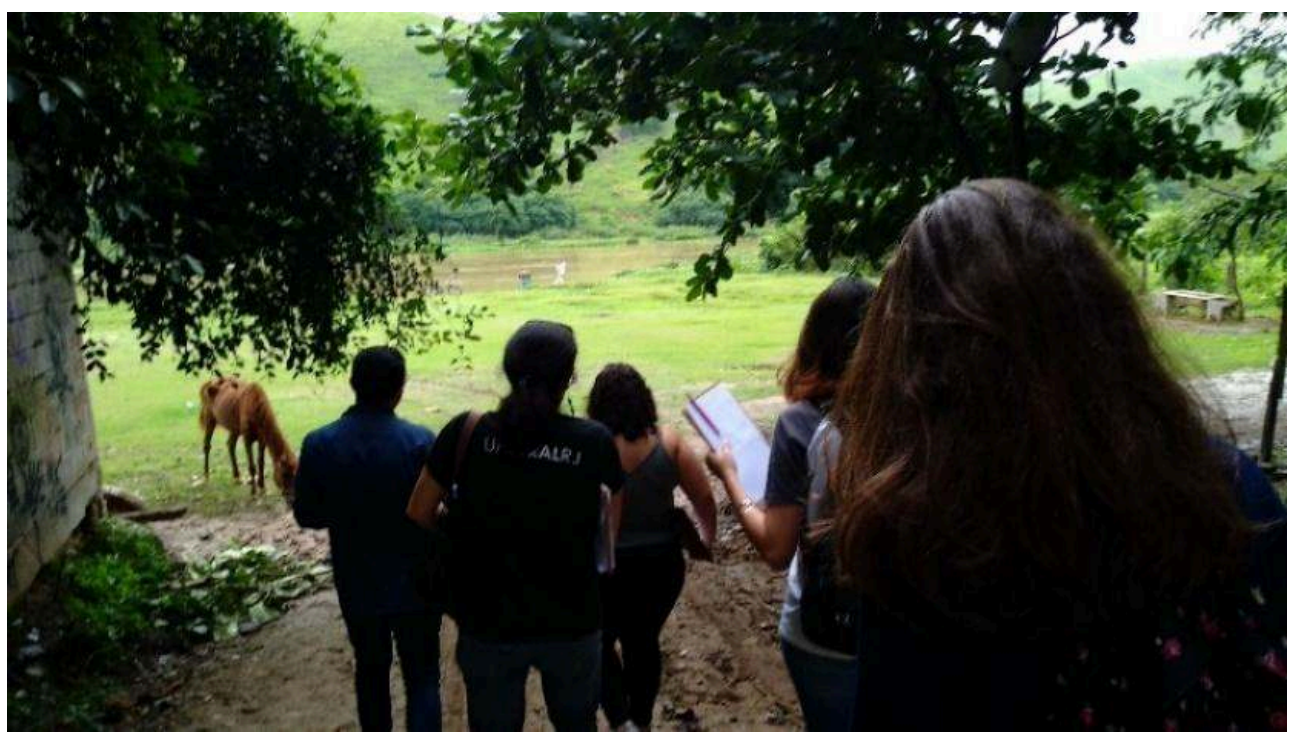

Fonte: Acervo GEDUR, Dez/2018. 
Figura 6 - Visita de Campo realizada em Japeri em dezembro de 2018: Mapeamentos in loco

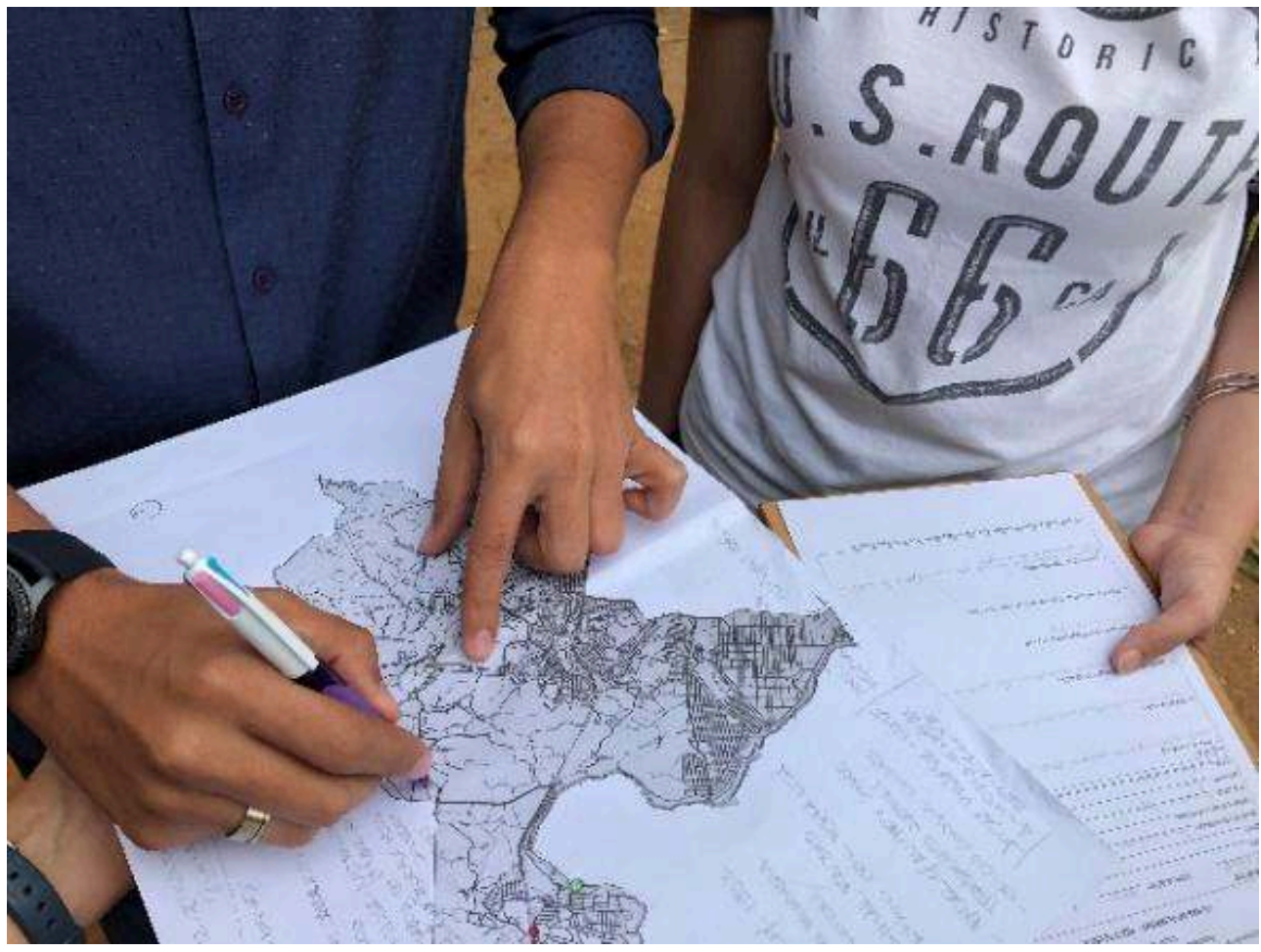

Fonte: Acervo GEDUR, Dez/2018.

Figura 7 - Visita de Campo: Pedra Lisa e campinho de pelada

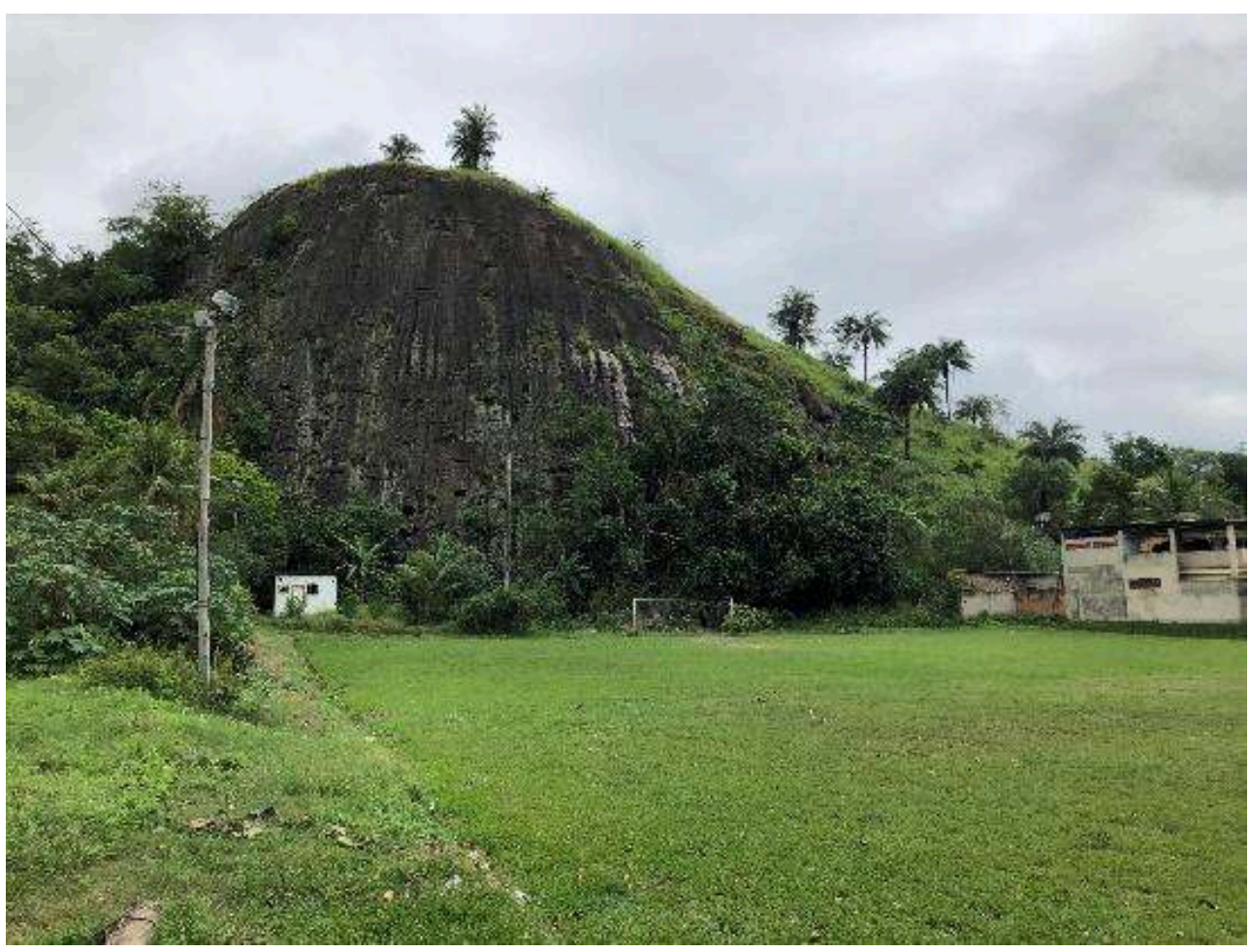

Fonte: Acervo GEDUR, Dez/2018. 
Figura 8 - Visita de Campo: Aspectos urbanísticos

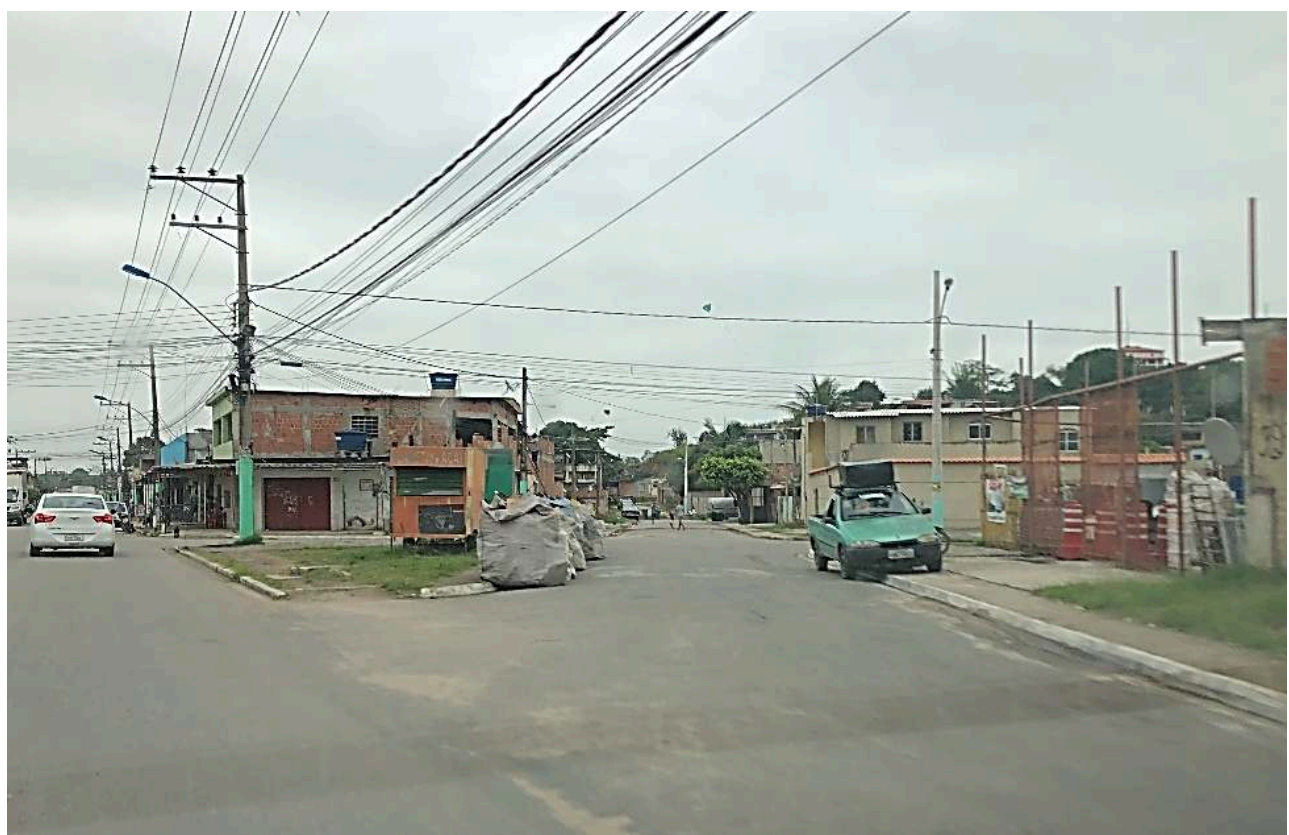

Fonte: Acervo GEDUR, Dez/2018.

Os dois pólos demográficos principais, Japeri e Engenheiro Pedreira, têm características próprias e a população os distingue como cidades distintas. Japeri abriga $28 \%$ da população, enquanto Engenheiro Pedreira comporta $72 \%$, segundo dados fornecidos pelo Secretário de Urbanismo ${ }^{9}$, que acompanhou a visita. Há uma proposta da prefeitura de transformar Japeri em polo turístico e Engenheiro Pedreira em $\mathrm{m}$ polo industrial e agrícola, devido a sua maior densidade demográfica e existência da Zona Industrial (ver Fig. 2). Além disso, há interesse na interligação dos dois pólos com uma ciclorrota, a fim de melhorar e dinamizar a mobilidade urbana intramunicipal, que atualmente conta com poucas e precárias linhas de ônibus. Esse seria ainda o eixo almejado para expansão urbana, interligando os dois núcleos. A principal ação desde a emancipação nesse sentido foi a instalação da sede da Prefeitura Municipal na Estrada Ari Schiavo, que os conecta. Porém, como observado, até o momento, a esperada integração urbana ainda não ocorreu, ainda que a expansão da mancha urbana de Japeri tenha dado um salto quantitativo de forma extensiva tentacular, entre $2010 \mathrm{e}$ 2020, como indica o mapa abaixo (Fig. 9). 


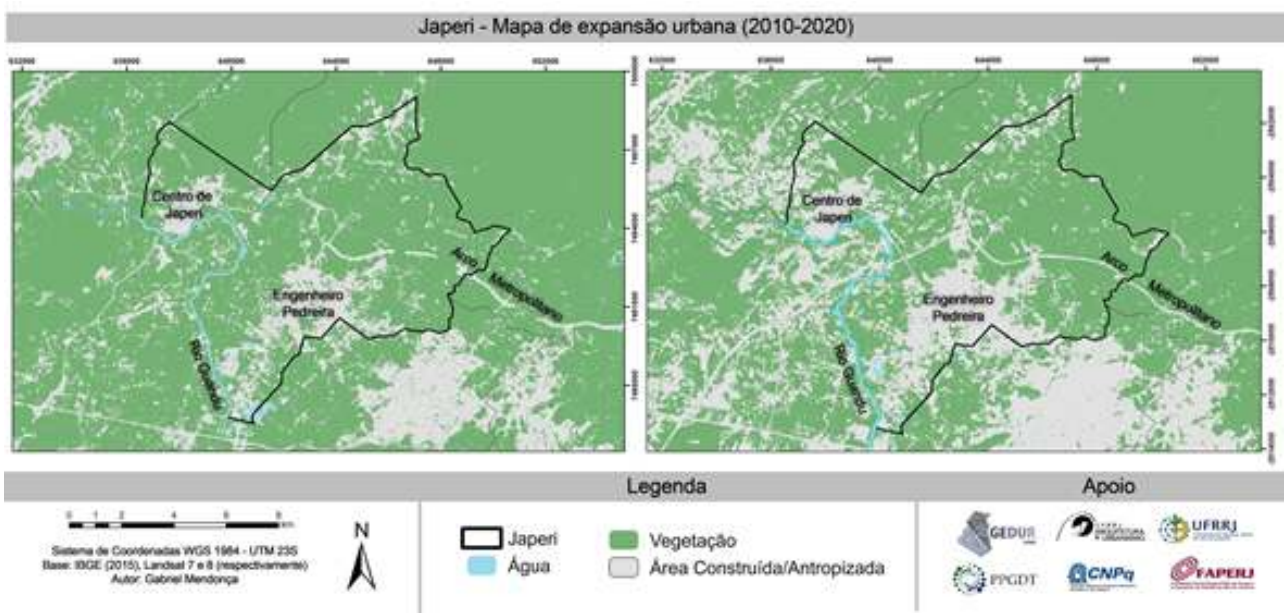

FONTE: Acervo GEDUR

A visita de campo foi fundamental para a coleta de dados e para a percepção do lugar, uma vez que puderam ser observadas as fragilidades e identificadas potencialidades, permitindo uma análise mais acurada do contexto urbano e possibilitando assim um melhor entendimento das problemáticas urbanas para a elaboração dos mapas e análises espaciais realizadas posteriormente.

Assim, foram realizados mapeamentos a partir de levantamentos de campo e bases cadastrais oficiais, com uso de geotecnologias livres sobre os aspectos biofísicos, tipomorfológicos (espaciais) e de planejamento do município, relativo ao macrozoneamento. A espacialização dos dados foi realizada com a plataforma ArcGis, além de tecnologias livres, e a cartografia permite uma visualização mais precisa das potencialidades e das fragilidades identificadas e sua relação com a produção da cidade, as questões de mobilidade e acessibilidade, as unidades morfoterritoriais (SILVA et al., 2015) e algumas inferências sobre a pobreza e violência urbana.

A estrutura física do município apresentada nas Figura 2 e 9, indicando os usos do solo, a estrutura viária, bem como as manchas de áreas florestadas e expansão urbana, deixa clara a proporção de espaços livres de edificações ainda existentes em relação às manchas urbanizadas.

O mapa abaixo (Fig. 10) destaca a tipologia morfológica em grelha do tecido urbano e os principais equipamentos urbanos e demonstra ainda mais claramente a segregação entre os dois núcleos principais. No mapa estão indicados ainda os principais equipamentos urbanos e pontos notáveis. Nota-se o adensamento construtivo nos núcleos ocupados horizontalmente, tendo as edificações mais altos apenas quatro pavimentos. Como indicado nos dados da Tabela 2, as vias públicas apresentam apenas 26,8\% de urbanização (pavimentação, iluminação pública, drenagem), há rarefeita presença de arborização urbana $(25,7 \%)$ e apenas $68,7 \%$ de esgotamento adequado, o que impacta o microclima local, especialmente nas áreas urbanizadas e contaminam os rios e aquíferos que drenam a região. 
Figura 10 - Mapa de núcleos urbanizados (centralidades) e serviços públicos em Japeri no entorno das duas estações ferroviárias - Editado pelos autores em ArcGis

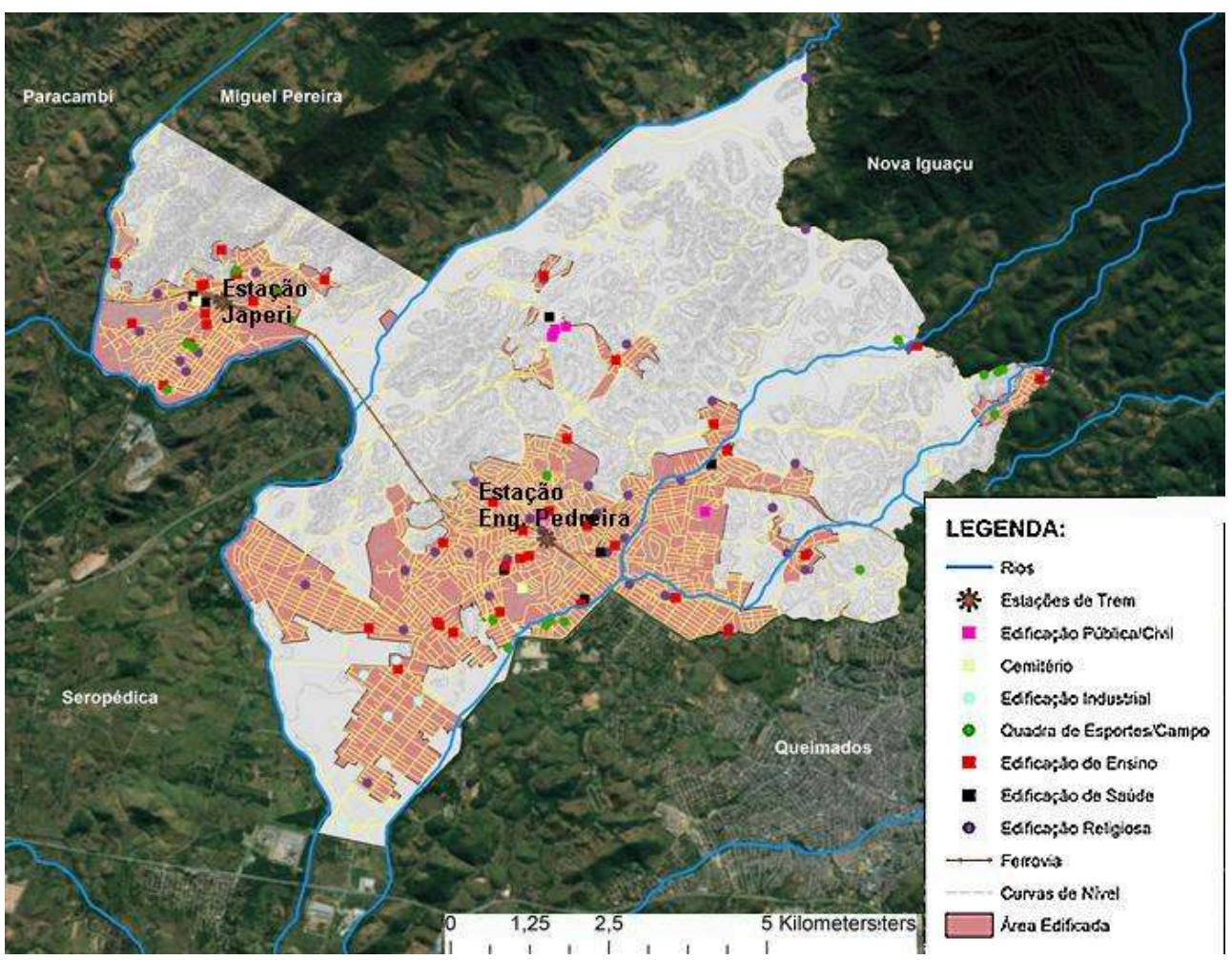

Fonte: Acervo GEDUR. relação à pobreza e à violência e corroborada pelos dados levantados (Casa Fluminense, 2020). Como complementação a essa análise, foi realizado levantamento de notícias jornalísticas, tanto de jornais de grande circulação, quanto da mídia local e regional, em relação às ocorrências policiais e sua localização no município. As ocorrências foram cartografadas espacialmente e sobrepostas sobre dados de sistema viário, estrutura urbana e uso do solo (Fig. 11).

O município de Japeri apresenta grande instabilidade política e carências não resolvidas pela governança pública nas últimas gestões. Essas problemáticas, além de sua histórica exploração industrial, estão refletidas em sua urbanidade. Dessa maneira, a desigualdade social, promovida pelo Estado em anos de negligência e falta de investimentos, é agravante em um cenário que submete a população a condições precárias e à violência urbana. Assim, buscou-se comparar as áreas de maior e menor incidência com elementos morfológicos visando perceber possíveis influências sobre a violência urbana no município, uma das mazelas enfrentadas devido também a ação do poder paralelo e consequentemente os enfrentamentos com as forças policiais do Estado.

40 A análise espacial propicia a demanda por políticas públicas e soluções de desenho urbano que favoreçam maior resiliência na questão do uso e apropriação dos espaços livres públicos, ou seja, ruas, praças, largos, etc., que são os normalmente apropriados pela população para circulação e atividades cotidianas ligadas ao lazer e às interações sociais. A espacialização dos dados proporcionada pelos mapas permite uma 
visualização mais precisa dos bairros mais vulneráveis à violência e suas fragilidades urbanas, bem como indica as potencialidades de desenvolvimento urbano.

Figura 11 - Mapa da violência em Japeri, elaborado a partir de fontes jornalísticas sobre base aerofotogramétrica

MAPA DE VIOLÊNCIA - JAPERI

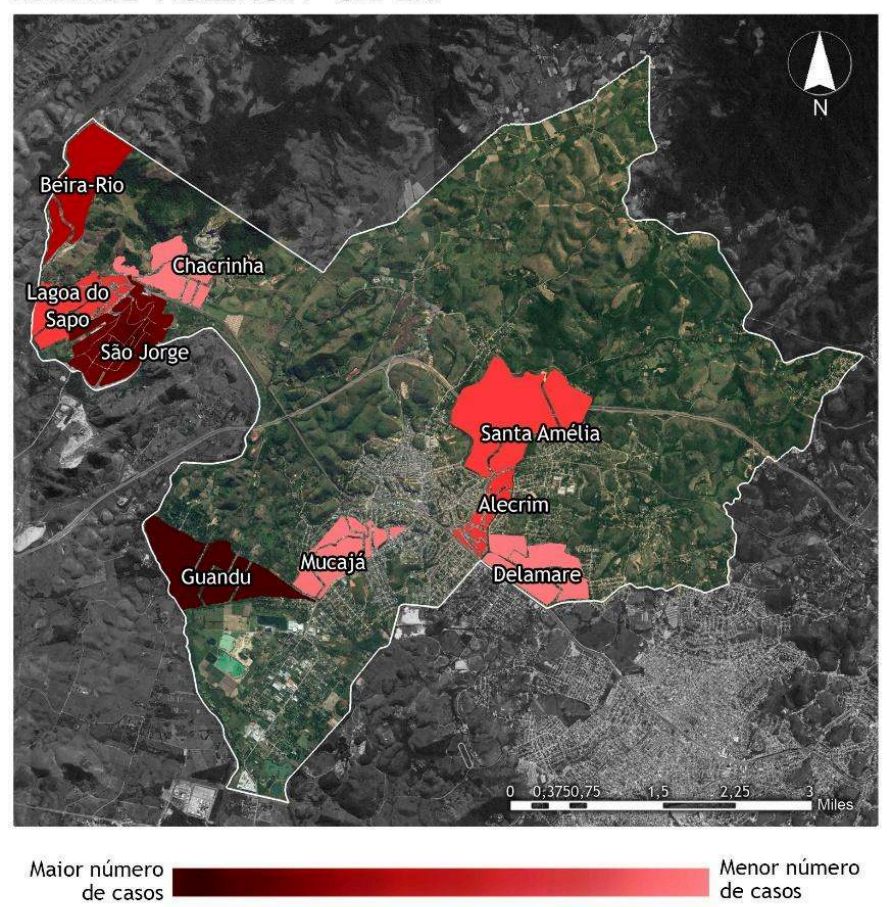

Fonte: Edição dos autores em ArcGis, 2019.

\section{O urbano, o turismo e a produção de alimentos - potencialidades e resiliência}

41 Apesar do estigma da violência e das carências infraestruturais e urbanas, foram identificadas potencialidades e oportunidades, tanto de caráter urbanístico, quanto patrimonial e cultural, turístico e estético, quanto pela existência de grandes glebas de caráter rural, não edificadas ou urbanizadas, designados espaços livres de edificações.

Japeri possui sítios arqueológicos e patrimônio edificado - histórico e pré-colonial como a Estação Ferroviária de Japeri, tombada pelo IPHAN/RJ e em processo de restauração (REIS e ALCANTARA, 2019). A estação é simbólica para a história da cidade, pois seu desenvolvimento ocorreu a partir da implantação da ferrovia e até hoje configura-se como um ponto nodal e marco referencial (LYNCH, 2011).

No mapa abaixo são identificados os sítios arqueológicos e o patrimônio edificado e ambiental de Japeri (Fig. 12).

Destacam-se também os potenciais ecoturísticos, turismo de aventura e turismo rural. Sem equipamentos urbanísticos ou estrutura turística adequada, o uso e apropriação desses espaços denotam um caráter insurgente, de sublimação, de capacidade de abstração da realidade hostil cotidiana. O Rio Guandu oferece suas águas poluídas para 
atividades náuticas; ali se pratica a canoagem e em suas margens a pesca e outras atividades de lazer. Valem menção especial, as áreas florestadas de Mata Atlântica e as áreas de proteção ambiental, como a Pedra Lisa e o Pico da Coragem, onde são realizadas atividades de escalada e rapel, vôo livre e trilhas, inclusive com competições organizadas pela Secretaria Municipal de Esporte, Turismo e Lazer de Japeri.

Figura 12 - Mapa com identificação de sítios arqueológicos e patrimônio histórico em Japeri

SÍTIOS ARQUEOLÓGICOS, PATRIMÔNIO EDIFICADO E AMBIENTAL DE JAPERI
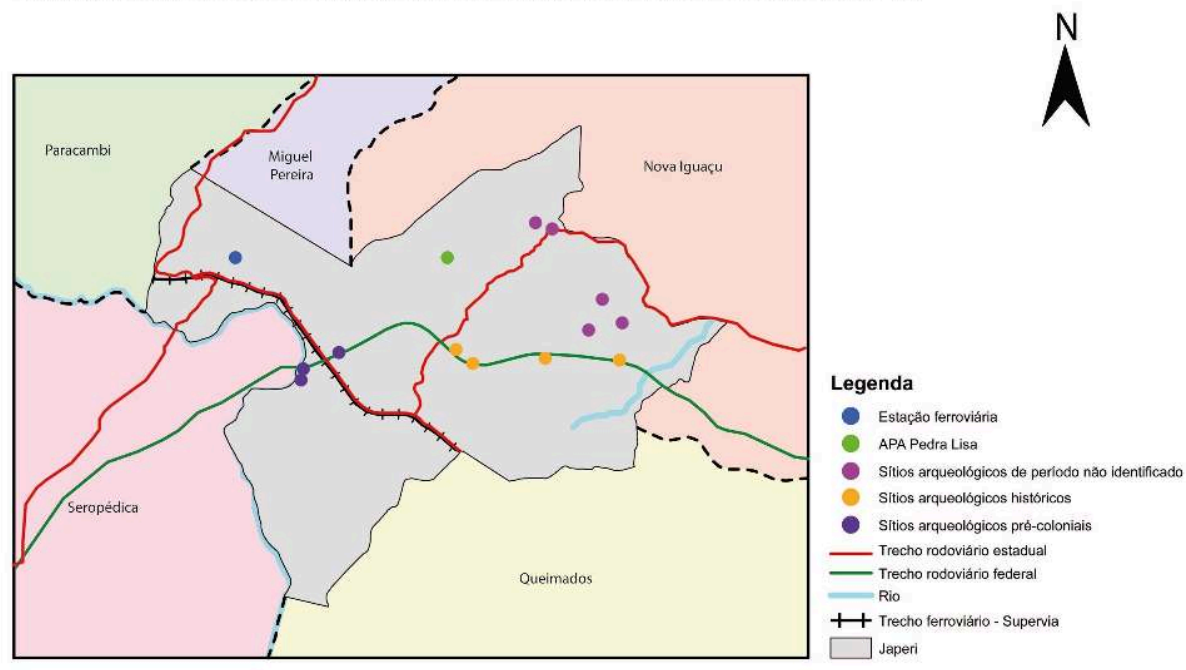

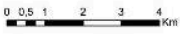

Fonte: Reis e Alcantara (2019)

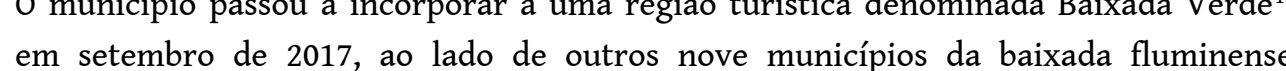
(Belford Roxo, Queimados, Nova Iguaçu, Duque de Caxias, Magé, Mesquita, São João de Meriti, Nilópolis e Seropédica). A pretensão do projeto é incentivar o turismo em toda a Baixada Fluminense, fomentando a economia e o desenvolvimento municipal. De acordo com técnicos da Secretaria, o relatório elaborado por pesquisadores do Instituto Multidisciplinar da UFRRJ, em Nova Iguaçu, contempla o diagnóstico e propostas, mas não havia sido disponibilizado publicamente até a escritura deste artigo.

No Estado do Rio de Janeiro, o turismo contribui para 4,9\% do PIB. A cidade do Rio de Janeiro, cartão postal nacional, destina grande parte de seu orçamento para mobilidade urbana, que alimenta o setor turístico. Acreditamos que o estímulo ao potencial turístico da região pode ser uma alternativa para o desenvolvimento econômico e urbano do município, o que contribuiria para o PIB municipal e estadual, com estímulo de setores alimentícios - bares e restaurantes - transportes, hotelaria e atividades culturais e de lazer.

Questões relacionadas à mobilidade urbana e acessibilidade se tornam assim muito importantes, uma vez que o investimento nessas áreas garante funcionamento, não apenas do setor turístico, mas de acesso aos serviços e equipamentos urbanos como um todo. Japeri apresenta os piores índices de desenvolvimento humano e de bem-estar 
urbano do Estado, agravada pela baixa taxa de empregabilidade e oferta de emprego em relação a população residente. As mulheres, principalmente as negras, são as mais afetadas pelo tempo de deslocamento pendular, devido a rotina assumida como força de trabalho sem qualificação e mal remunerado, ainda mais em relação ao homem, no centro metropolitano (Casa Fluminense, 2020).

Como visto, os municípios perimetropolitanos fluminenses apresentam potencialidades turísticas, culturais, sociais, econômicas, que merecem e precisam ser exploradas. No que tange à questão urbano-rural presente no território de Japeri, foram identificados vários "coletivos" e movimentos sociais, que mantém contato com as lideranças comunitárias e agrárias da região. Alguns deles são o Mobiliza Japeri, a ONG Casa Fluminense, conselhos comunitários e associações de moradores, comerciais e de agricultores, cujas ações vêm sendo realizadas para fomentar o debate, a inclusão social e a participação na importante questão da permanência das atividades agropastoris agricultura familiar, agricultura orgânica - que hoje sofrem pressão da expansão econômica e industrial.

Em outubro de 2018, foi realizado o Fórum Rio Japeri, organizado pela ONG, que contou com a presença de diversos coletivos, agremiações locais e regionais e acadêmicos. No evento, várias mesas de debates foram formadas e uma delas era justamente sobre a questão agrária. Moradores agricultores do bairro de Marajoara relataram as pressões que passaram a sofrer com a instalação de unidades fabris na zona delimitada no Plano Diretor como Área de Especial Interesse Industrial. A Região de Marajoara é estratégica para o escoamento da produção, em vista de sua proximidade com a via Dutra, porém, de acordo com os agricultores, possui um solo fértil, às margens do Rio Guandu, que vem sendo disputado para instalação de condomínios logísticos, com grandes perdas para as famílias que ali residem e produzem há décadas. A sequência de imagens abaixo demonstra o processo de transformação do bairro Cidade Jardim Marajoara, onde se localiza a fábrica da Casa Granado, na última década. Reitera-se que apesar dos dividendos financeiros para a cidade, a instalações industriais não são acompanhadas de qualquer investimento em termos de infraestrutura urbanística e saneamento ambiental (Figs. 13 e 14). 
Figura 13 - Imagem aerofotogramétrica do bairro Cidade Jardim Marajoara : jan/2009

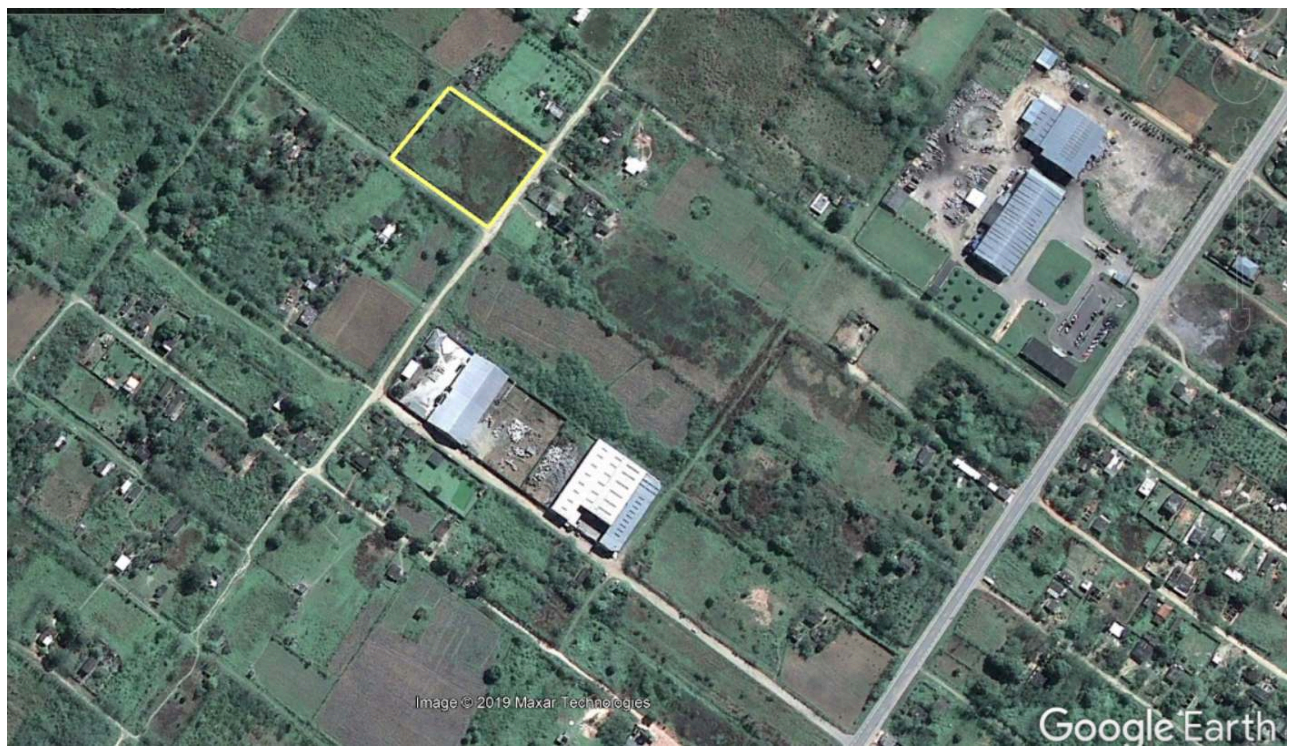

Fonte: Extraído do Google Earth e editado pelos autores (2019)

Figura 14 - Imagem aerofotogramétrica do bairro Cidade Jardim Marajoara : dez/2019 : note-se a transformação da área rural pela ocupação industrial

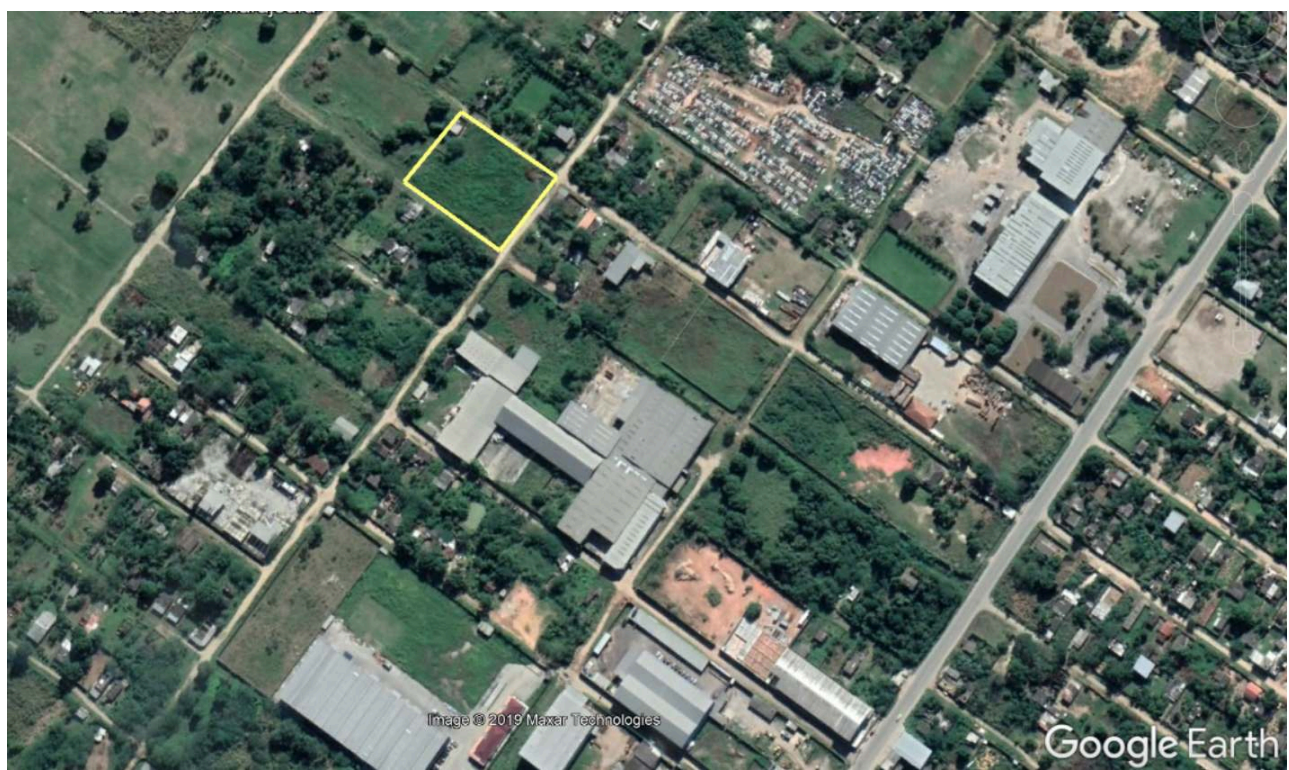

Fonte: Extraído do Google Earth e editado pelos autores (2019)

O caso dos agricultores do bairro Cidade Jardim Marajoara não é único nem isolado. Japeri conta com nove associações de produtores rurais, todos pequenos proprietários ou assentados pelo ITERJ. ${ }^{11}$ Os produtos dos agricultores são comercializados semanalmente na Feira de Agricultura Familiar de Japeri (Feira da Roça) e também no CEASA-RJ. As mulheres, mais uma vez, tornam-se protagonistas com ações cooperativadas que visam o empoderamento feminino no campo e o desenvolvimento sustentável. ${ }^{12}$ A Agroverde, Cooperativa de Produtores Rurais de Japeri, tem uma liderança feminina desde 2018 e vem buscando a melhoria da produção e ampliação da comercialização de seus produtos. A agricultura familiar e orgânica de pequeno porte 
representa a mais importante fonte de produção de alimentos no Brasil. As prefeituras são os principais compradores dos produtos agrícolas. Com recursos do PNAE Programa Nacional de Alimentação Escolar, devem adquirir pelo menos $30 \%$ dos alimentos diretamente dos produtores rurais. Japeri com sua rede de cooperativas pode garantir esse fornecimento, exigência nem sempre cumprida pela gestão municipal. Somente após recomendação do Ministério Público Federal, houve chamamento público para atender a comunidade escolar japeriense no último dia útil de 2018. ${ }^{13}$

51 Acreditamos que o desenvolvimento sustentado e equitativo e a justiça ambiental somente poderão ser alcançados com o fortalecimento das redes comunitárias e sociais de modo a pressionar o poder público e buscar o bem-viver almejado pela população (Veiga, 2006; Acselrad et al., 2009).

\section{Considerações Finais}

52 Percebe-se que apesar de caracterizar uma zona de sacrifício com limitadas políticas públicas que assegurem um melhor bem-estar urbano, Japeri possui expressivo potencial ambiental, urbanístico e agrícola, ofuscado pela imagem negativa propagada pela mídia e pela visão estatal de território de vocação industrial. Este artigo, buscou apresentar e analisar, por meio de cartografias espaciais, tais potenciais, bem como suas maiores fragilidades e ameaças.

A violência urbana é associada à falta de policiamento e gera o medo das pessoas que se protegem entre muros, evitando as ruas, entretanto, segundo Jacobs (2011) a intensificação da presença das pessoas nas vias incentivada pela requalificação dos espaços livres públicos, promove a vigilância natural e consequentemente a diminuição da violência.

54 A inclusão do município no mapa turístico do Rio de Janeiro destaca seu potencial para elaboração de projetos, promoção de eventos e apoio às iniciativas deste setor. No entanto, o atual cenário municipal, de acordo com relatos de moradores e levantamentos jornalísticos, ainda apresenta forte influência do estigma de pobreza e violência. De fato, as propostas fomentadoras de desenvolvimento urbano e turístico ainda são muito recentes para estabelecer uma relação com as políticas públicas e ações municipais. Assim, o desenvolvimento desta pesquisa visa incluir a participação social para a proposição cenários prospectivos a partir do olhar dos atores sociais e agentes públicos com apoio do material cartográfico e análises elaborados até o presente momento, a exemplo da atividade de extensão realizada em Seropédica e com aplicação da mesma metodologia (Alcantara, 2020).

55 Assim, a proposta de construção de cenários prospectivos a ser realizada na próxima etapa da pesquisa, visa incorporar a visão dos atores locais - habitantes, agentes públicos, conselhos comunitários - a partir da aplicação da ferramenta de cartografia social Oficina Participativa (Isidoro et al., 2011). Visa ainda a proposição de diretrizes de planejamento e soluções de desenho urbano de modo inclusivo que aprimorem a qualidade dos espaços públicos e possam garantir o bem-viver.

56 A resiliência do município e a insurgência de seus habitantes podem ser definidas pela constante luta contra os fatores que o determinam como uma zona de sacrifício. Acreditamos que este trabalho contribua na expectativa da transformação da realidade de Japeri que reside na atuação conjunta e integrada do poder público, nas políticas e 
ações que beneficiem a coletividade, da academia, fomentando estudos e pesquisas sobre suas potencialidades e promovendo fóruns integradores que integrem o olhar do habitante sobre seu lugar.

\section{Agradecimentos}

O presente trabalho foi realizado com apoio da Coordenação de Aperfeiçoamento de Pessoal de Nível Superior - Brasil (CAPES) - Código de Financiamento 001 e com apoio financeiro da FAPERJ com a Bolsa Jovem Cientista de Nosso Estado (Proc. E-26/202.706/2018). Agradecemos ainda à FAPERJ e ao CNPq pelas bolsas de Iniciação Científica aos discentes colaboradores da pesquisa do Grupo GEDUR-UFRRJ, nomeadamente Beatriz Corrêa, Fernanda Marchon, Gabriel Rodrigues, Lígia Magalhães e Emanuela Reis.

\section{BIBLIOGRAFIA}

ACSELRAD, Henri; MELLO, Cecília Campello do A.; BEZERRA, Gustavo das Neves (orgs). o que é justiça ambiental. Rio de Janeiro: Garamond, 2009. Ps. 11-45.

ALCANTARA, D. (2020). Estratégias e processos participativos para o desenvolvimento local e regional na Baixada de Sepetiba, RJ. Cadernos Metrópole. São Paulo, v. 22, n. 47, pp. 147-171, jan/ abr 2020.

ALCANTARA, D., SILVA, M.R., OLIVEIRA, N. A Periferia da Pobreza na Borda Oeste Metropolitana do Rio de Janeiro: ocupação, apropriação e (des)estruturação sócio-espacial e territorial. Anais do XVIII ENANPUR. Natal: UFRN, 2019.

ALMEIDA, S. Racismo Estrutural. Feminismos Plurais. São Paulo: Ed. Pólen, 2019.

BRITTO, A.L., FORMIGA-JOHNSSON, R.M., CARNEIRO, P.R.F. Abastecimento Público e Escassez Hidrossocial na Metrópole do Rio de Janeiro. Ambiente \& Sociedade. São Paulo v. XIX, n. 1 n p. 185-208 n jan.-mar. 2016.

CÂMARA METROPOLITANA. Projetos Estruturantes Integrados. Disponível em http:// www.camarametropolitana.rj.gov.br/projetosEstruturantes.asp Acesso em 19 abril 2018

JACOBS, Jane. Morte e Vida de Grandes Cidades. São Paulo: Martins Fontes, p.104. 2011.

IBGE CIDADES - Instituto Brasileiro de Geografia e Estatística. Disponível em https:// cidades.ibge.gov.br/brasil/rj/japeri/panorama. Acesso em 19/10/2019.

ISIDORO, I, ALCANTARA, D, TÂNGARI, V. Uma Inovação Metodológica no Estudo das Unidades de Paisagem: As Oficinas Locais nos municípios influenciados pelo Arco Metropolitano. In : Caderno de Resumos do V Colóquio QUAPÁ-SEL. São Paulo: FAUUSP, 2011.

LAGO, Luciana. A "periferia" metropolitana como lugar do trabalho: da cidade-dormitório à cidade plena. In : Cadernos IPPUR, Ano XXI, no. 2 Ago-Dez 2007. Rio de Janeiro: UFRJ/IPPUR, 2007. 
MAIA, P.F., RODRIGUES, A. A cidade (re)partida: um breve estudo sobre as emancipações da cidade de Nova Iguaçu e a formação da região da Baixada Fluminense. In : Anais 1‥ Congresso de Desenvolvimento Regional de Cabo Verde. Cidade da Praia: UniPiaget, 2009. Disponível em http:// www.apdr.pt/congresso/2009/pdf/Sess\%C3\%A3o\%2039/72A.pdf Acesso: 20 nov. 2019.

MAGNOLI, Miranda. Em busca de outros espaços livres de edificação. In: Revista Paisagem e Ambiente - Ensaios, no 21. São Paulo: FAUUSP, 2006, p. 143-173.

MARICATO, E. Brasil, cidades - alternativas para a crise urbana. Petrópolis, RJ: Vozes, 2001.

OBSERVATÓRIO. Base de Dados dos Município Brasileiros. Observatório das Metrópoles. 2019. Recuperado em 27 de setembro 2019 de https://ibeu.observatoriodasmetropoles.net.br/sobre/. OJIMA, Ricardo, SILVA, Robson B. da, PEREIRA, Rafael H.M. A mobilidade pendular na definição das cidades-dormitório: caracterização sociodemográfica e novas territorialidades no contexto da urbanização brasileira. In : Cadernos IPPUR, Rio de Janeiro, Ano XXI, no. 2, 2007, p. 111-132.

PNUD (2013) Atlas do Desenvolvimento Humano do Brasil. Disponível em http:// www.atlasbrasil.org.br/2013/pt/ Acesso: 23 abr. 2019.

REIS, E.; ALCANTARA, D. Patrimônio, Identidade e Territorialidade: o SIG na proposta de uma nova imagética para Japeri. In : Anais do 3o. Simpósio Científico ICOMOS/BRASIL. Belo Horizonte: UFMG, 2019

RIBEIRO, M. Desigualdades urbanas e desigualdades sociais nas metrópoles brasileiras. Sociologias, Porto Alegre, ano 18, no 42, mai/ago, 2016. pp. 198-230. Disponível em http://www.scielo.br/pdf/ soc/v18n42/1517-4522-soc-18-42-00198.pdf Acesso: 25 de julho de 2019

ROLNIK, Raquel. o que é cidade? São Paulo: Brasiliense, 2009.

SILVA, J. M.P., LIMA, F. e MAGALHÃES, N. Aplicação do conceito de Unidade Morfo-territorial na escalas metropolitana, intraurbana e local. In: Revista de Morfologia Urbana, 3(2), 105-20, 2015.

SILVA, Lucia. Entre Laranja e Gente: Notas Preliminares sobre Urbanização na Baixada Fluminense. In : Anais XVII ENANPUR. São Paulo: FAUUSP, 2017. Disponível em http:// anpur.org.br/xviienanpur/principal/?page_id=1298. Acesso em 23/07/2018

SILVA, R.A., BUENO, L. Injustiça Urbana e Ambiental: O Planejamento de "Zonas de Sacrifício". Anais do XV ENANPUR. Recife: UFPE, 2013

SOUZA, M.L. Os conceitos fundamentais da pesquisa sócio-espacial. Rio de Janeiro: Bertand Brasil, 2015.

TÂNGARI, Vera R.; SCHLEE Mônica B.; ANDRADE, Rubens de. (Org.). Sistema de espaços livres - o cotidiano, apropriações e ausências. Rio de Janeiro : FAU/UFRJ-PROARQ, 2009, v.1. p.496.

TÂNGARI, Vera, BUENO, Laura. Mapeamentos temáticos, classificação e categorização de dados. In : Anais ENANPARQ 2012 - II Encontro da Associação Nacional de Pesquisa e Pós-Graduação em Arquitetura e Urbanismo. Natal: UFRN, 2012.

TCE. Estudos Socioeconômicos dos municípios do Estado do Rio de Janeiro - Japeri - 2011. Secretaria de Planejamento do Estado do Rio de Janeiro - 2011.

VEIGA, J.E. Desenvolvimento Sustentável - o desafio do século XXI. Rio de Janeiro: Garamond, 2006. 


\section{NOTAS}

1. Pesquisa financiada com bolsa FAPERJ, JCNE (Processo no. E-26/202.706/2018)

2. Grupo de Pesquisa em Transformação de Uso, Ocupação e Desenvolvimento Urbano e Regional, baseado na Universidade Federal Rural do Rio de Janeiro

3. Conforme notícia no Portal do Iphan, de 18/05/2020. Disponível em http:// portal.iphan.gov.br/rj/noticias/detalhes/5686/restauro-da-estacao-de-japeri-rjresgata-o-patrimonio-ferroviario-fluminense Acesso: 25/05/2020.

4. Disponível em https://web.archive.org/web/20091019092248/http:// br.geocities.com/zostratus10/rio-trem.htm Acesso: 20 nov. 2019

5. Disponível em http://vfco.brazilia.jor.br/ferrovias/ estrada.de.ferro.central.do.brasil/memoria-historica-1908/0757-estacao-ferroviariaBelem-atual-Japeri.shtml Acesso: 13/04/2020

6. Os depoimentos foram coletados durante realização do Curso de Políticas Públicas promovido pela ONG Casa Fluminense, em setembro de 2019, em Japeri, no qual um dos autores participou.

7. Disponível em https://casafluminense.org.br/mapa-da-desigualdade/ Acesso em 20/07/2020.

8. Sobre a situação do prefeito de Japeri, ver artigo de O Globo disponível em https:// oglobo.globo.com/rio/preso-por-associacao-ao-trafico-prefeito-de-japeri-deixa-cadeiamas-nao-pode-entrar-na-prefeitura-24004748. Sobre a morte do vereador ver artigo de O Globo - Rio de Janeiro, de 24/03/2019 disponível em https://g1.globo.com/rj/rio-dejaneiro/noticia/2019/03/24/vereador-de-japeri-e-assassinado-na-regiaometropolitana-do-rj.ghtml Acesso em 21 nov. 2019.

9. Durante uma das visitas ao município, o Secretário de Urbanismo esteve presente e colaborou com informações valiosas sobre a história e o desenvolvimento local.

10. Em 2018, foi lançado o Programa Baixada Verde, um projeto de extensão da UFRRJ, com o apoio da Secretaria Municipal de Esporte, Turismo e Lazer de Japeri. O programa visa a identificação de potenciais turísticos em toda a Baixada Fluminense e a proposição de ações que mobilizem a população a ocupar os espaços, fomentando o turismo.

11. Ver artigo no jornal Extra, disponível em https://extra.globo.com/noticias/rio/ agricultores-com-mais-de-60-anos-em-japeri-mostram-forca-vontade-detrabalhar-21515361.html; acesso 20/07/2019.

12. Disponível em https://nacoesunidas.org/grupo-de-mulheres-amplia-lideranca-emcooperativa-de-produtores-rurais-de-japeri-rj/ acesso em 20/07/2019.

13. Disponível em https://www.correiodalavoura.com/2019/07/prefeitura-assinacontrato-para.html acesso 20/07/2019. 


\section{RESUMOS}

Este artigo apresenta e analisa potencialidades e fragilidades socioambientais e o impacto de políticas públicas sobre o território e a produção urbana de Japeri, RJ, município do Oeste Metropolitano Fluminense. Os desafios de ordem política, urbana e social são amplificados por desigualdades socioespaciais; precariedades infraestruturais, de saneamento e urbanísticas; e carências de serviços públicos de assistência à população, determinantes no baixo ranqueamento de IBEU e IDHM no Estado. A construção do Arco Metropolitano e o estímulo à industrialização, em nível federal e estadual, sem restrições legislativas em nível municipal, reforçam sua designação como zona de sacrifício, agravada pela pobreza e violência urbanas. Na análise, são aplicados conceitos de metropolização, periferização, desenvolvimento urbano sustentável e justiça ambiental e incorporados a evolução urbana de Japeri; dados socioeconômicos e aspectos demográficos; mapeamentos temáticos elaborados a partir de levantamentos de campo e bases cadastrais, com uso de geotecnologias livres e SIG; e análise espacial de aspectos tipomorfológicos. Um mapa de violência foi gerado a partir de levantamento em fontes jornalísticas, que se concentram nos conflitos e crimes, ampliando o estigma de território hostil e perigoso. Auxiliares na construção de cenários prospectivos que integram a última etapa da pesquisa, os mapeamentos são auxiliares nos processos de planejamento e gestão municipal na perspectiva participativa. Ressalta-se o caráter insurgente de ativismos sociais e institucionais locais, em face da realidade vigente, bem como a identificação de potencialidades territoriais: requalificação de centralidades e espaços públicos; promoção do turismo e lazer, e do patrimônio cultural e natural; produção agrícola familiar nas glebas rurais. Embora preliminares, espera-se que os resultados contribuíam no fomento da resiliência e qualidade urbana e na promoção da cidadania.

This article presents and analyzes socioenvironmental strenghts and weaknesses and the impact of public policies on the territory and urban production of Japeri, RJ, municipality of the Metropolitan West of Rio de Janeiro. Political, urban and social challenges are amplified by sociospatial inequalities; precarious infrastructures, sanitation and urban planning; and shortages of public assistance services to the population, determinants in the low ranking of Urban Welfare and Human Development Indexes in state level. The Metropolitan Ring Road construction and the encouragement of industrialization, at the federal and state level, without legislative restrictions at the municipal level, reinforce its designation as a sacrificial zone, aggravated by urban poverty and violence. In the analysis, concepts of metropolization, periphery, sustainable urban development and environmental justice are applied and incorporated into the urban evolution of Japeri; socioeconomic data and demographic aspects; thematic mappings elaborated from field surveys and cadastral bases, using free geotechnologies and GIS; and typomorphological aspects and spatial analysis. A map of violence was generated from a survey in journalistic sources, which focus on conflicts and crimes, increasing the stigma of hostile and dangerous territory. Auxiliary in the construction of prospective scenarios of the last stage of the research, the mappings are auxiliary in the planning and municipal management processes in the participatory perspective. The insurgent character of local social and institutional activisms is highlighted, in view of the current reality, as well as the identification of territorial potentialities: requalification of centralities and public spaces; promotion of tourism and leisure, and cultural and natural heritage; family agricultural production in rural areas. Although preliminary, the results are expected to contribute to the promotion of urban quality and resilience and to the promotion of citizenship. 
Este artículo presenta y analiza las potencialidades y debilidades socioambientales y el impacto de las políticas públicas en el territorio y la producción urbana de Japeri, RJ, municipio del Oeste Metropolitano Fluminense. Los desafíos políticos, urbanos y sociales se ven amplificados por las desigualdades socioespaciales; precarias infraestructuras, de saneamiento y urbanismo; y escasez de los servicios de asistencia pública a la población, determinantes en el bajo ranking del IBEU y el IDH en el Estado. La construcción del Arco Metropolitano y el impulso a la industrialización, a nivel federal y estatal, sin restricciones legislativas a nivel municipal, refuerzan su denominación como zona de sacrificio, agravada por la pobreza y la violencia urbana. Utilizamos en el análisis los conceptos de metropolización, periferización, desarrollo urbano sostenible y justicia ambiental, e incorporamos al entendimiento de la evolución urbana de Japeri; datos socioeconómicos y aspectos demográficos; mapeos temáticos construidos a través de estudios de campo y bases catastrales, utilizando geotecnologías libres y SIG; y análisis espacial de aspectos del tipo morfológico. Se elaboró un mapa de violencia a partir de una encuesta realizada por fuentes periodísticas, que se enfoca en conflictos y crímenes, aumentando el estigma de territorio hostil y peligroso. Auxiliares en la construcción de escenarios prospectivos que integran la última etapa de la investigación, los mapeos son auxiliares en los procesos de planificación y gestión municipal en la perspectiva participativa. Se destaca el carácter insurgente de los activismos sociales e institucionales locales, ante la realidad actual, así como la identificación de potencialidades territoriales: recalificación de centralidades y espacios públicos; promoción del turismo y el ocio, y del patrimonio cultural y natural; producción agrícola familiar en zonas rurales. Aunque es preliminar, se espera que los resultados contribuyan a la promoción de la calidad y la resiliencia urbanas y a la promoción de la ciudadanía.

Cet article présente et analyse les potentialités et faiblesses socio-environnementales et l'impact des politiques publiques sur le territoire et la production urbaine de Japeri, RJ, municipalité de l'Ouest Métropolitain de Rio de Janeiro. Les enjeux politiques, urbains et sociaux sont amplifiés par les inégalités socio-spatiales et les infrastructures précaires, surtout l'assainissement et l'urbanisme, ainsi que les pénuries de services d'assistance publique à la population, déterminants de son faible classement à l'IBEU et IDHM dans l'État. La construction du « Arco Metropolitano » et la promotion de l'industrialisation, au niveau fédéral et étatique et sans restrictions législatives au niveau municipal, renforcent sa désignation de zone de sacrifice, qui est aggravée par la pauvreté urbaine et la violence. Dans cette analyse, les concepts de métropolisation, de périphérie, de développement urbain durable et de justice environnementale sont appliqués et incorporés dans l'évolution urbaine de Japeri ; données socio-économiques et aspects démographiques; des cartographies thématiques élaborées à partir d'études de terrain et de bases cadastrales, à l'aide de géotechnologies et de SIG gratuits ; et aspects typomorphologiques et analyse spatiale. Une carte de la violence a été produite à partir d'une enquête dans des sources journalistiques, qui se concentrent sur les conflits et les crimes et qui accroissent sa stigmatisation comme un territoire hostile et dangereux. Auxiliaires dans la construction de scénarios prospectifs de la dernière étape de la recherche, les cartographies sont auxiliaires dans les processus de planification et de gestion municipale dans une perspective participative. Le caractère insurgé des activismes sociaux et institutionnels locaux est mis en évidence, au regard de la réalité actuelle, ainsi que l'identification des potentialités territoriales : requalification des centralités et des espaces publics ; promotion du tourisme et des loisirs, ainsi que du patrimoine culturel et naturel ; production agricole familiale en milieu rural. Bien que préliminaires, les résultats devraient contribuer à la promotion de la qualité et de la résilience urbaines et à la promotion de la citoyenneté. 
ÍNDICE

Palavras-chave: zona de sacrifício, desenvolvimento urbano, vulnerabilidades sociais, Japeri-RJ.

Mots-clés: Zone de sacrifice ; développement urbain ; vulnérabilités sociales, Japeri-RJ.

Keywords: Sacrificial zone, Urban development, Social vulnerabilities, Japeri-RJ.

Palabras claves: zona de sacrificio, desarrollo urbano, análisis de tipo morfológico;

vulnerabilidades sociales, Japeri-RJ.

\section{AUTORES}

\section{DENISE DE ALCANTARA}

Professora do Departamento de Arquitetura e Urbanismo e do Programa de Pós-Graduação em Desenvolvimento Territorial e Políticas Públicas e Pesquisadora Líder do Grupo GEDUR, da Universidade Federal Rural do Rio de Janeiro, Mestre e Doutora pelo PROARQ-UFRJ e Bolsista de Produtividade JCNE-FAPERJ com a pesquisa Territórios e Paisagens Perimetropolitanos: conflitos e desigualdades sócio-espaciais e cenários prospectivos no Rio de Janeiro na perspectiva da Nova Agenda Urbana 2030.E-mail: denisedealcantara@gmail.com.

\section{NATÁLIA DA SILVA OLIVEIRA}

Mestranda do Programa de Pós-Graduação em Desenvolvimento Territorial e Políticas Públicas, Especialista em Política e Planejamento Urbano pelo IPPUR/UFRJ e Arquiteta-Urbanista pela Universidade Federal Rural do Rio de Janeiro. E-mail: nsoliveira.arq@gmail.com

\section{LÍGIA CASTANHEIRA MAGALHÃES}

Graduanda e Bolsista de Iniciação Científica no Departamento de Arquitetura e Urbanismo da Universidade Federal Rural do Rio de Janeiro.

E-mail: ligiacastanheira.m@gmail.com.

\section{GABRIEL RODRIGUES DE MENDONÇA}

Graduando e Bolsista de Iniciação Científica no Departamento de Arquitetura e Urbanismo da Universidade Federal Rural do Rio de Janeiro. E-mail: gabriel.rodriguesdm@gmail.com. 